\title{
Choque circulatório em equinos
}

\section{Circulatory shock in horses}

\author{
Ubiratan Pereira de Melo ${ }^{1 *}$; Cíntia Ferreira ${ }^{1}$; \\ Maristela Silveira Palhares²; José Monteiro da Silva Filho²
}

\section{Resumo}

Choque circulatório pode ser definido como uma falha circulatória aguda com liberação inadequada de oxigênio e nutrientes aos tecidos, resultando em hipóxia celular. O choque pode ser classificado como cardiogênico, obstrutivo, hipovolêmico ou distributivo. As consequências fisiopatológicas da perfusão tecidual inadequada estão diretamente relacionadas à isquemia celular, liberação inadequada de $\mathrm{O}_{2}$ e produção de potentes mediadores inflamatórios. Caso as anormalidades de perfusão tecidual se perpetuem, a função de vários órgãos se torna inadequada. A consequente reperfusão poderá exacerbar a disfunção orgânica e, nos casos graves, culminar na síndrome da disfunção orgânica múltipla. $\mathrm{O}$ reconhecimento precoce de equinos em choque circulatório e o fornecimento imediato de suporte circulatório efetivo são essenciais. Em todos os casos o objetivo é restaurar a perfusão e a liberação de oxigênio aos tecidos, enquanto se corrige a causa primária. A demora em fazer o diagnóstico e iniciar o tratamento, bem como a ressuscitação sub-ótima, contribuem para o desenvolvimento de falha vascular periférica e alterações irreversíveis na utilização de oxigênio, culminando na disfunção orgânica.

Palavras-chave: Equino, fluidoterapia, hipovolemia, perfusão tecidual, mediadores inflamatórios

\begin{abstract}
Circulatory shock can be defined as an acute circulatory failure with an inadequate tissue delivery of oxygen and nutritive substrates to the tissues, resulting in generalised cellular hypoxia. Shock can be classified as cardiogenic, obstructive, hypovolaemic, or distributive. The pathophysiologic consequences of inadequate tissue perfusion are directly related to cell ischemia, inadequate $\mathrm{O}_{2}$ delivery, and the production of proinflammatory mediators. If abnormalities of tissue perfusion are allowed to persist, the function of vital organs will be impaired. The subsequent reperfusion will exacerbate organ dysfunction and, in severe cases, may culminate in multiple organ dysfunction syndrome. Early recognition of equine that are shocked and immediate provision of effective circulatory support is therefore essential. In all cases the objective is to restore oxygen delivery to the tissues while correcting the underlying cause. Delays in making the diagnosis and initiating treatment, as well as suboptimal resuscitation, contribute to the development of peripheral vascular failure and irreversible defects in oxygen use which can culminate in vital organ dysfunction.
\end{abstract}

Key words: Equine, fluid therapy, hypovolaemia, inflammatory mediators, tissue perfusion

1 Médico Veterinário - Doutorando - Programa de Pós-graduação em Ciência Animal - Escola de Veterinária da UFMG. Bolsista do CNPq. e-mail: ubiratan_melo@yahoo.com.br

2 Professor associado - Departamento de Clínica e Cirurgia Veterinárias - Escola de Veterinária da UFMG.

* Autor para correspondência 


\section{Introdução}

O choque circulatório faz parte da via final de inúmeras doenças na espécie equina, eé caracterizado pela incapacidade do sistema circulatório fornecer oxigênio e nutrientes aos tecidos de forma a atender suas necessidades metabólicas. Um aspecto a ser considerado é que nem todos os danos teciduais resultantes do choque advêm da hipóxia, mas, também, decorrem da baixa oferta de nutrientes, depuração reduzida de substâncias tóxicas, maior afluxo de substâncias nocivas aos tecidos, ativação de mecanismos lesivos e ineficiência dos mecanismos compensatórios (MOORE, 1990; MUIR, 1998).

O choque circulatório é identificado pela sintomatologia clínica (depressão, palidez de mucosas, taquicardia, taquipnéia, pulso periférico fraco e extremidades frias), no entanto, esses sinais clínicos representam simples manifestações de um complexo mecanismo fisiopatológico. A manifestação clínica varia entre equinos adultos e neonatos, mas, independente da idade, mudanças no nível de consciência ocorrem 2-3 horas após o início do choque (CORLEY; AXON, 2005).

O diagnóstico e tratamento do choque constituem-se num dos principais problemas nas unidades de terapia intensiva. Nos estágios iniciais, a ressuscitação vigorosa pode corrigir a hipóxia tecidual, permitindo a reversão do choque. Entretanto, se a perfusão e o transporte de oxigênio continuarem diminuídos, a lesão celular pode tornar-se irreversível. Mesmo com tratamento adequado muitos pacientes morrem nas primeiras 48 horas após o início do choque em decorrência da síndrome da resposta inflamatória sistêmica (SRIS) e síndrome da disfunção orgânica múltipla (SDOM) (MARSON et al., 1998; MUIR, 1998).

Este artigo tem por objetivo revisar os aspectos relevantes do choque circulatório na espécie equina abordando a classificação, fisiopatologia, diagnóstico e tratamento.

\section{Revisão de literatura}

\section{Classificação do choque circulatório}

Originalmente, o choque foi classificado de acordo com o mecanismo responsável pelo seu desenvolvimento (hipovolemia secundária a perda de fluido, falha cardíaca, sepse e reações de hipersensibilidade). Desordens endócrinas e neurogênicas são descritas como causas de choque nos seres humanos, no entanto, não há descrição do papel dessas desordens nos equinos (DEVEY; CROWE JR., 1997). A classificação do choque obedece a uma finalidade estritamente didática, pois a maioria dos quadros mostra mais de um componente em sua evolução (MARSON et al., 1998; MUIR, 1998; MELO et al., 2008):

Hipovolêmico - caracterizado por baixo volume intravascular relativo à sua capacitância, ou seja, hipovolemia relativa ou absoluta. Pode ser causado por hemorragia, sequestro de fluido, diarréia, sudorese excessiva e desidratação. O volume contido no compartimento intravascular é inadequado para a perfusão tecidual. Há diminuição do débito cardíaco em virtude da diminuição da pré-carga e da pressão arterial média. Como mecanismos compensatórios ocorrem aumentos da contratilidade, resistência vascular sistêmica (RVS) e frequência cardíaca.

Cardiogênico - existe limitação primária no desempenho cardíaco decorrente de interferências sobre o inotropismo e/ou cronotropismo, e a função cardíaca é insuficiente para manter o débito cardíaco em níveis compatíveis com as necessidades metabólicas. Este tipo de choque ocorre secundário à falência do ventrículo esquerdo por infarto agudo do miocárdio, cardiopatias, arritmias graves e causas metabólicas (hipocalcemia e hipoglicemia, por exemplo).

Obstrutivo - resulta de bloqueio mecânico ao fluxo sanguíneo na circulação pulmonarou sistêmica, podendo ser causado por tamponamento cardíaco, pneumotórax ou aneurisma. O choque obstrutivo 
tem como mecanismos compensatórios aumento da pré-carga, da RVS e da frequência cardíaca.

Distributivo - caracterizado pelo desequilíbrio entre a demanda tecidual e a oferta de oxigênio por alteração na distribuição do fluxo sanguíneo. Dessa forma, há tecidos com fluxo sanguíneo elevado em relação à sua necessidade e outros com fluxo sanguíneo elevado em termos numéricos, mas insuficiente para atender às necessidades metabólicas. É decorrente de causas neurológicas (trauma cerebral), uso de drogas vasodilatadoras, anafilaxia, doenças endócrinas. A vasodilatação ocasiona diminuição da RVS, com diminuição do retorno venoso e do débito cardíaco. Para compensar este estado hemodinâmico, ocorre aumento da contratilidade e da frequência cardíaca.

Séptico - trata-se de um tipo de choque resultante da descompensação hemodinâmica produzida pela presença de agentes infecciosos ou seus mediadores (endotoxinas) na circulação. Há diminuição da pré-carga pelo sequestro de líquido, diminuição da pós-carga por vasodilatação, lesão celular direta e disfunção miocárdica. Como mecanismos compensatórios, ocorrem aumento da frequência cardíaca e do débito cardíaco.

O choque circulatório pode se apresentar na forma hipodinâmica (frio) ou hiperdinâmica (quente). Pacientes em choque hipodinâmico apresentam tônus vascular aumentado e baixo débito cardíaco, enquanto aqueles em choque hiperdinâmico apresentam vasodilatação periférica e débito cardíaco alto (DRIES, 2007). Embora o fluxo sanguíneo esteja aumentado no choque hiperdinâmico, a vasodilatação é tão intensa que resulta em perfusão tecidual inadequada. $\mathrm{O}$ choque hiperdinâmico é a principal causa de perfusão tecidual inadequada nos potros e em equinos adultos após cirurgia de lesões intestinais estrangulantes. A fase hipodinâmica ocorre após a hiperdinâmica e é caracterizada pela rápida deterioração dos parâmetros clínicos do paciente em decorrência do baixo fluxo sanguíneo e baixa perfusão tecidual
(SOUTHWOOD, 2004).

Durante a fase hiperdinâmica ocorre hiperventilação e congestão das mucosas, além da elevação do tempo de perfusão capilar e da temperatura corporal. Alguns animais podem apresentar broncoconstrição. Nesta fase ocorre a formação de desvios arteriovenosos (shunts) em vários órgãos, agravando o quadro de isquemia tecidual. A fase hipodinâmica é caracterizada clinicamente por hipotermia, taquicardia, elevação do tempo de perfusão capilar, mucosas pálidas ou cianóticas, acidemia e hipoxemia (GREEN; ADAMS, 1992).

Muitos fatores estão envolvidos na transição da fase hiperdinâmica para a hipodinâmica. Aparentemente, o mais importante é a diminuição da resposta orgânica à adrenomodulina. O papel exato da adrenomodulina necessita ser definido mais claramente, mas sabe-se que este peptídeo possui atividade cardio-depressora. Outros fatores envolvidos são a liberação de citocinas, depressão do miocárdio mediada pelo óxido nítrico, extravasamento de proteína e fluido através do endotélio vascular, além da hipovolemia e fluxo sanguíneo coronário inadequado. Quando esses fatores se associam, a elevação do débito cardíaco que ocorre na fase hiperdinâmica não pode mais ser mantida e o choque hipodinâmico surge (WANG, 2001).

O choque hipovolêmico no equino é relativamente comum nos distúrbios gastrintestinais (diarréia, colite, íleo pós-operatório), após episódios de hemorragia e sequestros de líquidos (ascite, hidrotórax, hidropsia dos anexos fetais) (SEAHORN; SEAHORN, 2003; MELO et al., 2007ab). As causas mais comuns de choque hipovolêmico por hemorragia no equino incluem hemorragia pós-castração, ruptura de artéria uterina ou ilíaca e erosão da carótida interna por micose da bolsa gutural. Os sinais de choque em geral irão se desenvolver quando houver redução do volume sanguíneo superior a 30\% (MORRIS, 2000). 
O choque obstrutivo ocorre secundário a aneurismas por Strongylus vulgaris, que podem provocar tanto obstrução não estrangulante parcial ou completa quanto infarto das artérias mesentéricas resultando em cólica, isquemia intestinal e choque. Outras causas prováveis, porém, infrequentes, incluem a obstrução vascular por neoplasia, êmbolos pulmonares e tamponamento pericárdico (MUIR, 1998; MELO et al., 2008).

O choque anafilático é uma forma de choque distributivo definido como uma reação de hipersensibilidade a substâncias exógenas, geralmente fármacos. Relatos clínicos do choque anafilático no equino são raros, embora a falta de documentaçãocientíficanãoreflitasuarealocorrência. O mecanismo pelo qual o choque anafilático surge resulta da interação de antígenos e IgE na superfície de mastócitos sensibilizados, resultando na liberação de mediadores farmacologicamente ativos (cininas, prostaglandina, histamina, serotonina, leucotrienos e fator ativador de plaquetas). A ação desses mediadores resulta em vasodilatação, aumento da permeabilidade vascular, constrição do músculo liso e diminuição do débito cardíaco. Sistemicamente, isto é manifestado por mucosas congestas, hipotensão e estase venosa periférica. A hipotensão pode resultar em comprometimento cardiovascular moderado (baixo débito cardíaco, hipoperfusão periférica) ou choque irreversível e fatal (HORMANSKI, 1991; SWIDERSKI, 2000).

O choque séptico, antigamente denominado choque endotoxêmico, é uma complicação comum de doenças gastrointestinais (salmonelose, colite, obstrução estrangulante isquêmica e peritonite) (MOORE; MORRIS, 1992; FERREIRA et al., 2007; FERREIRA et al., 2009), e as endotoxinas liberadas pela bacteriólise gram-negativa têm papel fundamental no seu desenvolvimento. Embora associado a distúrbios gastrointestinais, esse tipo de choque pode ser sequela de infecções gramnegativas ou positivas, doenças fúngicas ou virais a exemplo da pleurite, pneumonia, metrite pós-parto, pericardite séptica e sepse neonatal (ROY, 2004; MELO et al., 2008).
O choque séptico é, primariamente, um tipo de choque distributivo caracterizado pela ineficiente liberação e extração de $\mathrm{O}_{2}$ tecidual associada com vasodilatação periférica independente do débito cardíaco normal ou aumentado. No choque séptico, ocorre uma complexa interação entre vasodilatação patológica, hipovolemia relativa e/ou absoluta, disfunção miocárdica e alteração da distribuição do fluxo sanguíneo secundário a resposta inflamatória à infecção e, mesmo após o restabelecimento da normovolemia, anormalidades microcirculatórias podem persistir (BEALE et al., 2004; DRIES, 2007).

A diminuição do retorno venoso no choque séptico não ocorre igualmente em todos os órgãos e, aparentemente, as vísceras são mais afetadas. Ocorre hipertensão portal secundária ao déficit do retorno venoso, e a combinação de déficit do retorno venoso e aumento da permeabilidade vascular resultam em hipovolemia grave, muitas vezes, refratária a reposição de fluídos. Com o agravamento da hipovolemia, o débito cardíaco diminui e ocorre redistribuição do fluxo sanguíneo para garantir a perfusão cardíaca e cerebral (DRIES, 2007). Independente do débito cardíaco aumentado durante a fase hiperdinâmica do choque séptico, o miocárdio é disfuncional. Tanto o ventrículo direito quanto o esquerdo podem dilatar, a função contrátil pode diminuir e a complacência ventricular é reduzida. Aparentemente, essa disfunção é mediada pelo óxido nítrico que se combina a radicais superóxido formando peroxinitrito, substância citotóxica para os miócitos (CORLEY, 2004). O óxido nítrico pode exercer efeitos inotrópicos negativos via GMP cíclico e disfunção na autoregulação coronária e utilização de $\mathrm{O}_{2}$ (VICENT et al., 2000).

\section{Fisiopatologia}

Diversos mecanismos estão associados ao desenvolvimento e perpetuação do choque circulatório (Figura 1) e, em alguns casos, refratariedade às diversas modalidades de 
tratamento instituídas. Entre estes mecanismos citase a isquemia/hipóxia tecidual, injúria de reperfusão, produção e liberação de radicais livres e mediadores inflamatórios, coagulação intravascular disseminada entre outros (MUIR, 1998).

Independente da causa, os vários tipos de choque circulatório incorporam a isquemia e má perfusão tecidual no seu desenvolvimento e perpetuação. A perfusão tecidual inadequada impede o metabolismo celular oxidativo e ativa potentes enzimas da membrana celular que aceleram a quebra dos fosfolipídios de membrana, resultando na formação de ácido araquidônico e consequente biosíntese e liberação de prostaglandinas, tromboxanos e leucotrienos (BOTTOMS; ADAMS, 1992).

\section{Isquemia, hipóxia tecidual e reperfusão}

A isquemia é definida como a redução ou interrupção do fluxo sanguíneo decorrente de constrição funcional ou obstrução mecânica dos vasos sanguíneos e se constitui numa das principais causas de lesão tecidual. As alterações celulares são diretamente relacionadas à duração da isquemia e quando essa se prolonga por tempo suficiente resulta em necrose celular (MOORE et al., 1995; MUIR, 1998).

A isquemia desencadeia alterações teciduais através da redução ou bloqueio da oferta de oxigênio, impedindo o metabolismo energético aeróbio. Esse fato determina a diminuição dos níveis intracelulares de ATP e distúrbio da homeostase celular. Em estados de higidez, a liberação de $\mathrm{O}_{2}$ para os tecidos é cerca de quatro vezes maior do que o consumo. Desta forma, existe uma margem de segurança antes que a redução no transporte de $\mathrm{O}_{2}$ afete adversamente a função tecidual durante estados de baixo fluxo sanguíneo e, consequentemente, hipóxia (MORRISON, 2006).

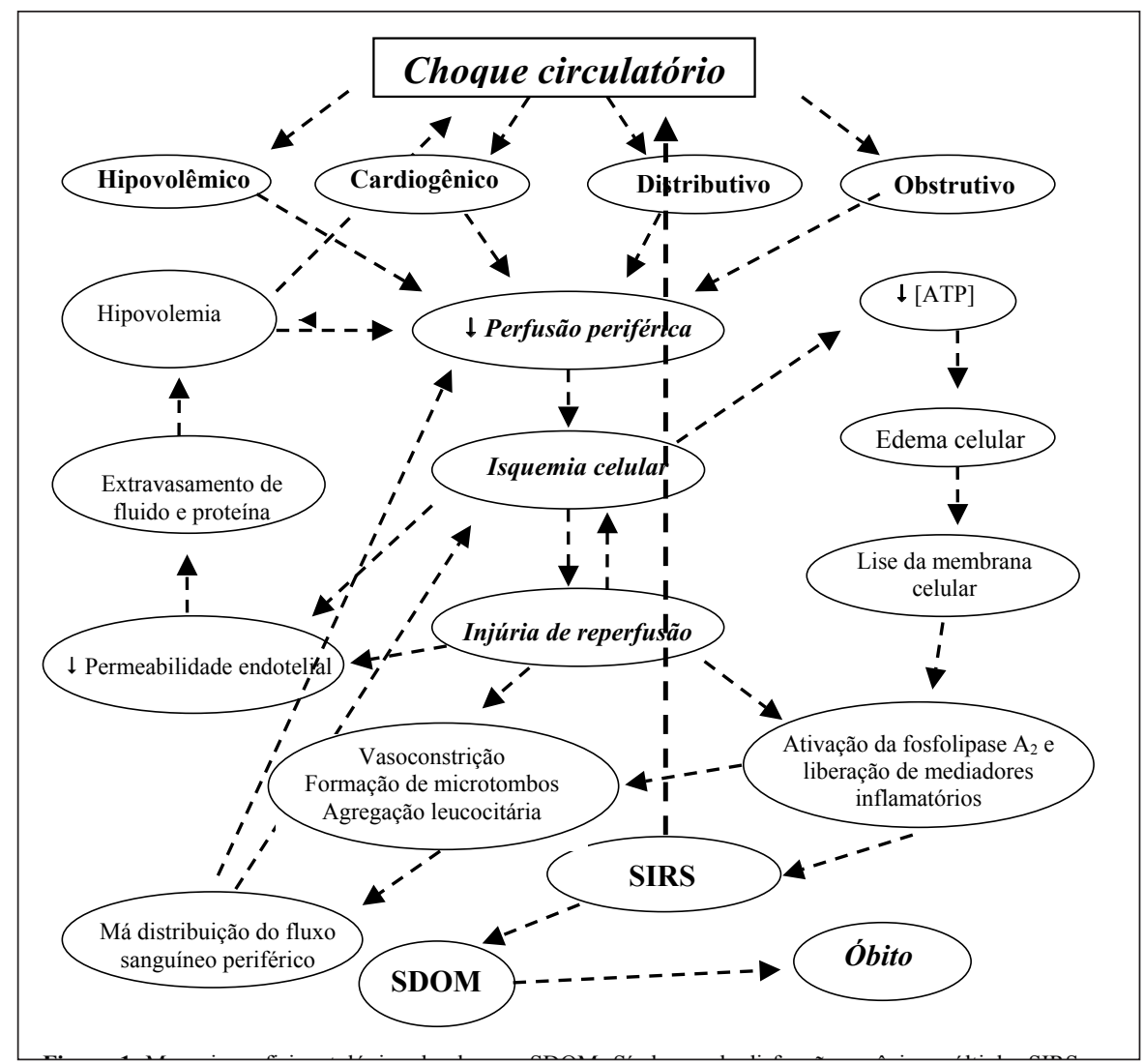

Figura 1. Mecanismo fisiopatológico do choque. SDOM: Síndrome da disfunção orgânica múltipla; SIRS: Síndrome da resposta inflamatória sistêmica. 
A otimização da liberação de $\mathrm{O}_{2}$ durante o choque circulatório é o ponto fundamental tanto para a sobrevivência quanto para a minimização da lesão orgânica e celular. Alguns órgãos adaptam-se para extrair altas concentrações de oxigênio pela redistribuição do fluxo sanguíneo na microcirculação. A regulação neurogênica do fluxo sanguíneo durante o choque é alterada pela liberação endógena de várias catecolaminas e mediadores inflamatórios. O tônus dos esfíncteres pré-capilares muda à medida que ocorre alteração da liberação de $\mathrm{O}_{2}$ aos tecidos. A constrição primária desses esfíncteres resultará em diminuição da liberação de oxigênio para determinados órgãos. À medida que a liberação de $\mathrm{O}_{2}$ tecidual diminui, os capilares "fechados" (vasoconstrição) abrem-se promovendo aumento da densidade de perfusão capilar, o que permite determinados órgãos extrair mais $\mathrm{O}_{2}$. A elevação da densidade capilar promove aumento da resistência dos capilares disponíveis para o fluxo sanguíneo. Este evento resulta em diminuição da velocidade do fluxo em cada capilar, permitindo, desta forma, mais tempo para a difusão do $\mathrm{O}_{2}$ (BASTERRECHEA; STEIN, 2000).

A diminuição do fornecimento de $\mathrm{O}_{2}$ pode lesar a maioria das células do organismo e danos celulares irreversíveis podem ocorrer após 15 minutos de hipóxia celular. A oxigenação tecidual inadequada prejudica a fosforilação oxidativa na mitocôndria resultando em diminuição da concentração de ATP em decorrência do metabolismo anaeróbico. Enquanto o metabolismo aeróbico produz 38 moles de ATP por mol de glicose consumida, apenas dois moles de ATP são produzidos por mol de glicose durante a glicólise anaeróbica (ROWE; WHITE, 2002; FRANKLIN; PELOSO, 2006).

A diminuição da concentração de ATP reduz a atividade das bombas de transporte iônico dependentes de energia $\left(\mathrm{Na}^{+}, \mathrm{Ca}^{++}, \mathrm{K}^{+}\right)$resultando em acúmulo intracelular de $\mathrm{Na}^{+}, \mathrm{Ca}^{++}, \mathrm{Cl}^{-}$e água. $\mathrm{O}$ acúmulointracelular deáguaresulta em edemacelular agudo. O edema celular destrói a matriz extracelular provocando ruptura das vesículas lisossômicas e consequente liberação de potentes enzimas reativas como elastase, catepsina, colagenase, fosfolipase $\mathrm{A}_{2}$, fosfolipase $\mathrm{C}$ e mieloperoxidade (McMICHAEL; MOORE, 2004; KEEL; TRENTZ, 2005). A ativação das fosfolipases $\mathrm{A}_{2}$ e $\mathrm{C}$ cataliza a liberação de ácido araquidônico a partir dos fosfolipídios de membrana. A perda da homeostase celular é eventualmente demonstrada pela similaridade entre a concentração intracelular de eletrólitos e a do fluido extracelular, com elevação da concentração intracelular de $\mathrm{Na}^{+}$, $\mathrm{Cl}^{-}, \mathrm{H}_{2} \mathrm{O}$ e diminuição da concentração de $\mathrm{K}^{+}$e $\mathrm{Mg}^{++}$ (FERRARI, 1992).

Outros eventos importantes ocorrem durante o evento isquêmico-hipóxico. A ativação do fator nuclear $\kappa B(\mathrm{NF} \kappa \mathrm{B})$ induz aumento da liberação de mediadores inflamatórios (citocinas, prostaglandinas, leucotrienos, etc.). A expressão aumentada de moléculas de adesão intracelular do tipo 1 (ICAM-1) e selectina E, via ativação do NFאB promove aumento da adesão de leucócitos ao local da isquemia durante a reperfusão. A inativação do óxido nítrico endotelial causa vasoconstrição e inibição da via da prostaglandina na cascata do ácido araquidônico favorecendo um quadro de vasoconstrição e agregação plaquetária. Todos esses eventos contribuem para a instalação e perpetuação do quadro de choque (McMICHAEL; MOORE, 2004).

Alesão do endotélio vascular induzida pela injúria isquêmica permite o extravasamento de fluido e albumina plasmática para o espaço intersticial. Isto não somente reduz a pressão oncótica intravascular, como também permite a albumina de exercer pressão oncótica no interstício resultando na retirada de mais fluido do compartimento intravascular. A vasodilatação resultante determinará maior volume vascular para o mesmo volume de fluido levando a um estado de hipovolemia relativa (GREEN; ADAMS, 1992; CORLEY, 2004).

O endotélio é particularmente vulnerável a injúria hipóxica e mudanças significativas ocorrem em 30 minutos. A hipóxia promove a ativação 
plaquetária e aderência dos leucócitos ao endotélio, contribuindo, desta forma, para o processo inflamatório e ativação da cascata da coagulação. Sob condições homeostáticas, o endotélio possui atividade pró e anticoagulante. No entanto, durante o choque circulatório, o endotélio passa a demonstrar atividade predominantemente pró-coagulante (PETERS et al., 2003). Embora seja necessária para a sobrevivência celular, a reperfusão cria mais injúria do que a isquemia em decorrência da grave disfunção endotelial que promove. A disfunção endotelial resulta da maciça formação de radicais livres, diminuição da liberação de óxido nítrico e acentuada liberação de endotelina, criando um estado de intensa vasoconstrição e consequente diminuição da perfusão periférica (MCMICHAEL; MOORE, 2004).

Além disto, a injúria de reperfusão promove distribuição desigual do fluxo sanguíneo para os capilares resultando em hipóxia tecidual focal. Fatores que podem ser responsáveis por essa má distribuição do fluxo sanguíneo incluem a trombose de microvasos, edema das células endoteliais, hemoconcentração intravascular, aumento da viscosidade sanguínea, resistência pós-capilar aumentada e edema intersticial induzido por compressão extravascular. Nas fases iniciais do choque, a hipóxia e lesões de reperfusão causam necrose dos enterócitos. A necrose dos enterócitos associada a alterações na permeabilidade endotelial permite a translocação bacteriana e de seus subprodutos. É provável que durante esta fase o tecido linfático entérico seja ativado, liberando mediadores inflamatórios como IL-1, IL-2, IL-4, IL-6, fator de necrose tumoral $\alpha$ (TNF- $\alpha$ ), histamina e lisosima (MUIR, 1998).

\section{Óxido nitrico e radicais livres}

$\mathrm{O}$ óxido nítrico (NO) é sintetizado por células endoteliais, macrófagos e outras células via oxidação da L-arginina pela enzima NO-sintetase (NOS). O NO apresenta duas isoformas, a constitutiva (cNOS) e a indutiva (iNOS). A NOS predominantemente encontrada nas células do endotélio vascular e neurônios é a cNOS. A ativação da cNOS é dependente da concentração de calmodulina e $\mathrm{Ca}^{2+}$. $\mathrm{O}$ NO é produzido pela cNOS dentro de segundos após a elevação da concentração de $\mathrm{Ca}^{2+}$ citosólico em resposta a ativação de receptores de superfície celular e mecanismos transmissores de sinais (PETERS et al., 2003). Existem duas isoformas de cNOS. A primeira é encontrada no endotélio vascular e é chamada de NOS endotelial (eNOS). Já a segunda é encontrada nos neurônios e chamada NOS neuronal (nNOS). No sistema nervoso, a nNOS é expressada no cérebro, gânglio simpático, medula e nervos nitrérgicos (nervos não-adrenérgicos nãocolinérgicos que liberam NO) (HOWE; BOOTHE, 2001).

O NO possui importante papel regulatório na dinâmica cardiovascular, defesa antimicrobiana, agregação plaquetária, adesão leucocitária, além da atividade fibrinolítica e trombolítica, além de regular a liberação de renina e a homeostase do $\mathrm{Na}^{+}$e $\mathrm{H}_{2} \mathrm{O}$ regulando, portanto, o volume vascular. A iNOS é irrelevante durante condições basais, porém é produzida em grandes quantidades pelos neutrófilos, hepatócitos, macrófagos, células do músculo liso vascular, células de Kupffer e condrócitos após exposição a agentes como endotoxina, citocinas e várias substâncias pró-inflamatórias (prostaglandina, histamina, etc). Cerca de duas a quatro horas são necessárias para a síntese e atividade biológica da iNOS após exposição a substâncias pró-inflamatórias (MUIR, 1998; VICENT et al., 2000).

Durante o choque circulatório, iNOS e adrenomodulina são produzidos pelas células do endotélio vascular culminando em vasodilatação, hipotensão e hiporeatividade vascular. Além disto, a ação dessas duas substâncias promove o desenvolvimento de desvios arteriovenosos e consequente má distribuição do fluxo sanguíneo. $\mathrm{O}$ rápido desenvolvimento desses desvios pode ser a razão primária para a rápida progressão e irreversibilidade do choque em alguns pacientes 
(MUIR, 1998). No entanto, a produção excessiva de NO pode apresentar efeitos benéficos incluindo vasodilatação, melhoria do fluxo sanguíneo na microcirculação, diminuição da agregação plaquetária e aderência leucocitária e melhora da resposta de defesa imune. Durante a fase aguda do choque, a produção de NO aumenta como resultado da ativação da eNOS, enquanto elevações posteriores são causados pela ativação da iNOS (HOWE; BOOTHE, 2001).

A presença de concentrações elevadas de nitrito/ nitrato, derivados estáveis do NO, nos pacientes em choque, combinado com a redução no tônus vascular, sugerem que o NO esteja envolvido nas alterações cardiovasculares desenvolvidas durante os estados de choque circulatório. O papel fisiopatológico do NO durante o choque pode compreender tanto alterações vasculares quanto efeitos citotóxicos diretos do NO ou substâncias relacionadas ao NO (VICENT et al., 2000).

As espécies reativas de oxigênio (ROS) são moléculas que contêm um oxigênio em estado altamente reativo, com capacidade oxidativa alta. Figuram entre as ROS, o ânion superóxido $\left(\mathrm{O}_{2}^{-}\right)$, o radical hidroxila $(\mathrm{HO})$ e o peróxido de hidrogênio $\left(\mathrm{H}_{2} \mathrm{O}_{2}\right)$. Independente de sua meia-vida curta, em média, milésimos de segundo, os radicais livres podem tornar-se estáveis e produzir reações biológicas lesivas (CARDOSO et al., 2006).

Vários processos biológicos como fagocitose, biosíntese de prostaglandinas e leucotrienos, além do transporte de elétrons produzem ROS. Sob circunstâncias controladas, a formação de ROS se inicia pela redução incompleta do oxigênio molecular por enzimas que incluem a xantina oxidase (converte xantinas em ácido úrico), óxido nítrico sintetase (NOS), cicloxigenase, NADPH oxidase e citocromo oxidase, assim como por vias mitocondriais. A produção endógena de ROS é controlada por mecanismos anti-oxidantes, compostos por enzimas e doadores de elétrons de baixo peso molecular (como ácido ascórbico, $\alpha$-tocoferóis e glutationa) que limitam a ação das ROS por eliminá-las ou repararem modificações oxidativas potencialmente danosas à célula (CARDOSO et al., 2006).

OspotentesefeitosdosROSnochoquecirculatório decorrem do aumento da permeabilidade da membrana celular induzido por esses radicais, lesão ao retículo sarcoplasmático causando inotropismo negativo, inibição da atividade da bomba $\mathrm{Na}^{+} / \mathrm{K}^{+}$ ATPase, inativação dos canais de $\mathrm{Na}^{+}$, aumento da peroxidação dos fosfolipídios de membrana e inativação da desidrogenase gliceraldeído-3-fosfato (PETERS et al., 2003).

\section{Mediadores inflamatórios}

A primeira citocina a aparecer na circulação na fase inicial do choque é o fator de necrose tumoral $\alpha$ (TNF- $\alpha$ ), produzido em grandes quantidades pelos macrófagos ativados. O TNF- $\alpha$ parece distribuirse preferencialmente para o fígado, rins, trato gastrointestinal e pele, onde interage com receptores celulares específicos. Uma vez na circulação, o TNF- $\alpha$ age sobre os neutrófilos aumentando sua atividade fagocítica, citotoxicidade e a produção do ânion superóxido e de $\mathrm{H}_{2} \mathrm{O}_{2}$, além de estimular a degranulação e a aderência dessas células ao endotélio, ativar a fosfolipase $\mathrm{A}_{2}$, desencadeiar a produção de fator ativador de plaquetas (PAF), aumentar a síntese de catecolaminas e induzir a expressão de antígenos de superfície das células endoteliais (KUESIS; SPIER, 2000; CAMPEBELL et al., 2007).

O TNF- $\alpha$ é responsável pelo desenvolvimento de hipotensão, hemoconcentração, acidose metabólica, coagulação intravascular disseminada e, eventualmente, morte. Nos estudos experimentais de endotoxemia, as concentrações séricas de TNF- $\alpha$ alcançam valores elevados duas horas após o início do insulto, retornando aos valores basais em torno de seis horas (FURR, 2003; ROY, 2004).

As células endoteliais, epiteliais e mononucleares fagocitárias, quando expostas à endotoxina, TNF- $\alpha$ 
ou leucotrienos liberam IL-1. Durante o choque circulatório, a IL-1 age ativando populações celulares do hospedeiro, participando com outras citocinas na indução da resposta de fase aguda, ativação da fosfolipase $\mathrm{A}_{2}$, catabolismo muscular, alterações hematológicas, ativação linfocitária e desarranjos endoteliais. Os picos da IL-1 acontecem 90 minutos após o pico do TNF- $\alpha$. Do mesmo modo do TNF- $\alpha$, a IL-1 tem espectro de atividade amplo e potente, sendo considerada uma candidata a induzir injúrias ao tecido do hospedeiro durante o choque, principalmente séptico (OLSON et al., 1995; ROY, 2004).

O TNF- $\alpha$ e a IL-1 induzem a transcrição de genes envolvidos na inflamação, tais como genes para outras citocinas, fosfolipase $\mathrm{A}_{2}$, cicloxigenase 2 , moléculas de adesão endotelial e quimocinas resultando na produção de vários mediadores inflamatórios (PAF, $\mathrm{PGE}_{2}$, leucotrienos) e a ativação dos neutrófilos, sua adesão ao endotélio e migração para os tecidos lesados, com consequente inflamação, destruição tecidual e perda da função. A IL-6 é produzida por vários tipos celulares após exposição ao TNF- $\alpha$ e IL-1, e sua concentração sérica aumenta rapidamente durante os estados de choque. A IL-6 é potente estimulante da resposta de fase aguda hepática e um fator de crescimento de linfócitos B (ROY, 2004).

Muitos dos mediadores inflamatórios do choque derivados dos lipídeos são associados ao metabolismo do ácido araquidônico (Figura 2). O ácido araquidônico é liberado de sua posição no fosfolipídio pela fosfolipase $\mathrm{A}_{2}$, e então metabolizado pela cicloxigenase ou pela lipoxigenase e a estrutura restante, a fosfatidilcolina, é convertida a fator ativador de plaquetas (PAF) pela acetiltransferase (MOORE; BARTON, 1998; KEEL; TRENTZ, 2005). Através da ação da prostaglandina sintetase, o ácido araquidônico é convertido a endoperóxidos cíclicos, $\mathrm{PGG}_{2}$ e $\mathrm{PGH}_{2}$. Essas moléculas são rapidamente convertidas a outros compostos incluindo tromboxano $\mathrm{A}_{2}\left(\mathrm{TXA}_{2}\right), \mathrm{PGI}_{2}$ e $\mathrm{PGF}_{2 \alpha}$ (OLSON et al., 1995).
O PAF funciona em processos fisiológicos normais bem como em processos inflamatórios. Nos estados de choque, o PAF induz hipotensão por diminuição do tônus vascular através de seus efeitos inotrópicos negativos, degranulação e agregação plaquetária, aumento da permeabilidade vascular, edema pulmonar e necrose intestinal isquêmica (KUESIS; SPIER, 2000).

Os efeitos biológicos do tromboxano ocorrem no início do choque e inclui broncoconstrição, vasoconstrição, agregação plaquetária, coagulação intravascular disseminada, micro-oclusão capilar periférica, diminuição da pressão sanguínea e má distribuição do fluxo sanguíneo. Embora tenha meia-vida curta, o tromboxano tem importante papel na patogênese do choque circulatório contribuindo para alterações hemodinâmicas e microvasculares que contribuem para o agravamento da isquemia tecidual (BOTTOMS; ADAMS, 1992).

A $\mathrm{PGI}_{2}$ inibe a agregação plaquetária, induz vasodilatação e contribui para o quadro de hipotensão sistêmica. Desarranjos da $\mathrm{PGE}_{2}$ afetam o fluxo sanguíneo regional, a função termoreguladora, a motilidade intestinal e a função imunológica. $\mathrm{O}$ papel dos diversos leucotrienos no choque séptico não está bem definido. O desafio séptico está associado com produção aumentada de leucotrienos e redução significativa no mecanismo de depuração hepato-biliar. Os principais efeitos dos leucotrienos são vasoconstrição, broncoconstrição e aumento da permeabilidade vascular (KUESIS; SPIER, 2000).

Além dos metabólitos do ácido araquidônico, muitas outras substâncias vasoativas foram sugeridas como mediadores do choque, tais como: histamina, serotonina, renina/angiotensina, bradicinina, anafilotoxinas, $\beta$-endorfinas, catecolaminas e fator depressor do miocárdio. No entanto, o papel destes mediadores no choque, principalmente séptico, não foram completamente caracterizados na espécie equina (KUESIS; SPIER, 2000). 


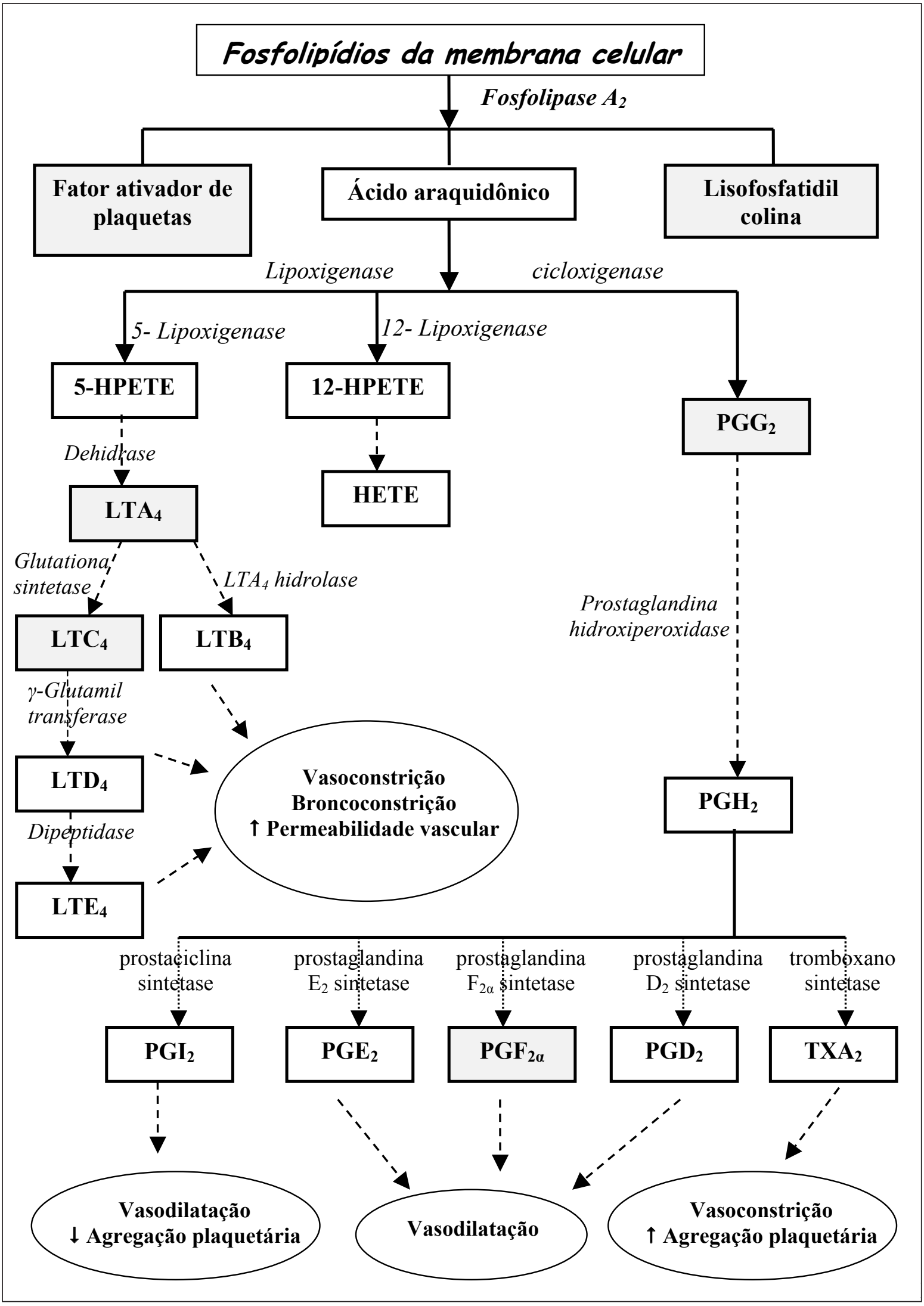

Figura 2. Produção de mediadores inflamatórios pelo metabolismo do ácido araquidônico e seus efeitos clínicos. 
Como consequência da ativação e liberação das citocinas, particularmente TNF- $\alpha$, IL-1 e IL-6, ocorre a indução da resposta da fase aguda. Esta resposta refere-se a produção hepática de proteínas que atuam facilitando os processos inflamatórios locais. As proteínas da fase aguda incluem as proteínas $\mathrm{C}_{3}$ e $\mathrm{C}_{4}$ do sistema complemento que são importantes na resposta imune inata a presença de bactérias ou seus sub-produtos (endotoxina, ácido lipotecóico), plasminogênio e fator ativador de plasminogênio tecidual (ambos com atividade anticoagulante), ceruroplasmina (ação antioxidante) e fibrinogênio. A atividade dessas proteínas pode desencadear coagulopatias, agravando ainda mais a perfusão tecidual (FURR, 2003).

\section{Coagulação intravascular disseminada}

A coagulação intravascular disseminada (CID) é caracterizada pela ativação difusa da coagulação intravascular, levando à formação e deposição de fibrina na microvasculatura. $\mathrm{O}$ sistema fibrinolítico está, em geral, afuncional durante a fase de maior ativação da coagulação, o que contribui para a deposição de fibrina. A deposição de fibrina ocasiona oclusão microvascular e consequente comprometimento da irrigação sanguínea de diversos órgãos, o que, em conjunto com alterações metabólicas e hemodinâmicas durante o choque circulatório, contribui para a SDOM (DALLAP, 2004).

A CID é uma complicação bem conhecida do choque séptico, exacerbando ainda mais o comprometimento circulatório. Existem três mecanismos que contribuem para o quadro de CID: (1) algumas citocinas, especialmente, IL-6, induzem a expressão maciça do fator tecidual (TF) na superfície dos macrófagos e células endoteliais, promovendo a síntese de trombina através da via extrínseca da coagulação; (2) os mecanismos naturais de inibição da coagulação (antitrombina, sistema da proteína $\mathrm{C}$ e inibidor da via do TF) estão inativos durante o choque séptico e (3) o sistema fibrinolítico, embora ativado inicialmente, é inibido através da liberação constante do inibidor/ativador de plasminogênio tipo 1 (PAM-1) (ROY, 2004).

Trauma grave também é frequentemente relacionado a CID e uma combinação de mecanismos, que inclui liberação de gordura e fosfolipídios tissulares na circulação, hemólise e lesão endotelial contribui para a ativação sistêmica da coagulação em tal situação. O padrão de liberação de citocinas em pacientes politraumatizados é semelhante àquele observado em pacientes sépticos, reforçando as evidências do seu papel fundamental no desenvolvimento da síndrome (PINTÃO; FRANCO, 2001).

A relação existente entre inflamação e coagulação é inquestionável. A reação inflamatória ativa a coagulação sanguínea por promover a expressão de fator tissular no espaço intravascular, eliciar a expressão de moléculas de adesão de leucócitos na parede vascular, diminuir a atividade fibrinolítica e a função da via anticoagulante da proteína $\mathrm{C}$. As citocinas são importantes mediadores dessas alterações e seu papel no desenvolvimento da CID vem se tornando cada vez mais claro. O papel do TNF- $\alpha$ na ativação da coagulação é relacionado à sua capacidade de induzir o aumento da IL-6. Adicionalmente, o TNF- $\alpha$ parece ser o principal mediador da depressão da atividade do sistema da proteína $\mathrm{C}$ por induzir diminuição da expressão de trombomodulina nas células endoteliais (PINTÃO; FRANCO, 2001).

A manifestação da CID irá variar de trombose difusa e insuficiência orgânica isquêmica à diátese hemorrágica grave. Microtrombose digital com isquemia costuma acompanhar a CID nos equinos e pode ter influência no desenvolvimento da laminite aguda. A tendência para trombose das veias periféricas é outra manifestação proeminente da disfunção coagulativa. Dependo da duração da CID, a depleção de plaquetas e fator coagulante e geração de subprodutos fibrinolíticos causam tendência a hemorragias (MORRIS, 2000). 
Os distúrbios do painel da coagulação refletem o estado de disfunção hemostática. São comuns os aumentos no tempo de protrombina (TP), tempo de trombina (TT) e no tempo de tromboplastina parcial ativada (TTPA), além de redução das concentrações plasmáticas de fibrinogênio, fator $\mathrm{V}$, Fator VIII, AT-III, plasminogênio, $\alpha_{2}$-antiplasmina e trombocitopenia. A combinação de trombocitopenia com TP e TTPA prolongados é fortemente indicativa de CID. A diminuição do fibrinogênio plasmático e elevação da concentração plasmática dos produtos da degradação da fibrina (PDF) estão associadas à fibrinólise aumentada. O aumento dos PDF reflete a ação proteolítica da plasmina sobre a fibrina (localmente) ou o fibrinogênio (sistemicamente) numa taxa que excede a depuração de PDF pelo sistema fagocitário mononuclear. A depressão da atividade da AT-III é um indicador consistente da coagulopatia e pode servir como um indicador de prognóstico negativo (MORRIS, 2000).

\section{Respostas compensatórias}

A resposta inicial do sistema cardiovascular às reduções na perfusão tecidual é um conjunto complexo de reflexos que servem para manter o tônus vascular e o débito cardíaco (MARSON et al., 1998). À medida que a pressão sanguínea diminui em resposta ao estado hipovolêmico, o organismo responde com intensa atividade simpática e parassimpática, liberando epinefrina, norepinefrina e dopamina na tentativa de restaurar a pressão sanguínea através de vasoconstrição e aumento do débito cardíaco. Concomitante a redução da perfusão tecidual, ocorre elevação da concentração sérica de catecolaminas, glucagon, cortisol, hormônio do crescimento, vasopressina, aldosterona, tiroxina e testosterona (DEVEY; CROWE JR., 1997).

$\mathrm{O}$ volume plasmático expande-se ante a retirada de líquido do interstício, aumento da reabsorção de $\mathrm{H}_{2} \mathrm{O}$ nos túbulos renais e absorção de líquido a partir do trato gastrintestinal. A queda inicial na pressão capilar decorrente da diminuição da volemia seguida por constrição arteriolar permite o movimento de proteína livre no espaço intersticial para os capilares. Aldosterona, junto com a vasopressina, diminui a perfusão renal na tentativa de conservar fluido e restaurar a pressão sanguínea (DEVEY; CROWE JR., 1997). A elevação dos níveis de catecolaminas estimula a secreção de glucagon, resultando em aumento da taxa de glicogenólise e consequente diminuição da glicose sanguínea, que por fim pode resultar em quadro hipoglicêmico de gravidade variável (MORRIS, 2000).

\section{Diagnóstico}

O diagnóstico do choque circulatório é basicamente clínico, baseando-se, portanto, numa boa anamnese e exame físico. Para seu diagnóstico, há a necessidade de identificarmos a presença de hipotensão arterial (pressão arterial sistólica (PAS) $<90 \mathrm{mmHg}$, pressão arterial média $(\mathrm{PAM})<60$ $\mathrm{mmHg}$ ou queda maior que $40 \mathrm{mmHg}$ na PAS) associada a sinais clínicos de perfusão tecidual inadequada (SIQUEIRA; SCHMIDT, 2003). A frequência cardíaca, pulso arterial, coloração de mucosas e tempo de preenchimento capilar são parâmetros comumente utilizados para avaliar o grau de comprometimento do sistema cardiovascular nos pacientes em choque, além de servirem como estimativas do grau de desidratação (Tab. 1), em associação com a mensuração do valor da proteína total e hematócrito (COOK; BAIN, 2003).

Outras mensurações de importância para o monitoramento de equinos em choque são a pressão arterial média, pressão venosa central, débito cardíaco, equilíbrio ácido-base, hematócrito e lactato plasmático (DIVERS, 2003). Em muitos casos, o choque circulatório é identificado pela sintomatologia clínica que inclui depressão, palidez ou congestão de mucosas, taquicardia, taquipnéia, pulso periférico fraco, estase venosa periférica e extremidades frias (HORMANSKI, 1991; SWIDERSKI, 2000). 
Tabela 1. Parâmetros utilizados para estimar o grau de desidratação nos equinos.

\begin{tabular}{ccccccc}
\hline Desidratação & FC & TPC & Mucosa & T. cutâneo & Ht (\%) & Pt (g/dl) \\
\hline $4 \%-6 \%$ & $\leq 40 \mathrm{bpm}$ & $1-2 \mathrm{seg}$. & úmida & $2-3 \mathrm{seg}$. & $40-50 \%$ & $6,5-7,5$ \\
$7 \%-9 \%$ & $40-60 \mathrm{bpm}$ & $2-4 \mathrm{seg}$. & pegajosa & $3-5 \mathrm{seg}$. & $50-65 \%$ & $7,5-8,5$ \\
$>9 \%$ & $>60 \mathrm{bpm}$ & $>4 \mathrm{seg}$. & seca & $>5 \mathrm{seg}$. & $>65 \%$ & $>8,5$ \\
\hline
\end{tabular}

FC: frequência cardíaca; TPC: tempo de perfusão capilar; Ht: hematócrito; Pt: proteína total.

Fonte: Adaptado de Seahorn e Seahorn (2003), Corley (2006) e Ferreira et al. (2009).

A frequência cardíaca do equino adulto varia de 28 a 40 batimentos por minutos e no potro neonato entre 70-105 batimentos por minutos (SPEIRS, 1999). A elevação da frequência cardíaca pode ser indicativa de hipovolemia, dor ou disfunção cardíaca. Todavia, a frequência cardíaca não deve ser utilizada isoladamente na avaliação do paciente em choque em decorrência da influência de outros fatores a exemplo da excitação e estresse. Deste modo, a frequência cardíaca é melhor avaliada quando mensurada conjuntamente com a coloração das mucosas, tempo de preenchimento capilar, qualidade e frequência do pulso e temperatura retal para identificar a presença e gravidade do choque circulatório (CORLEY; MARR, 2003; FERREIRA et al., 2009).

Nos potros, o desenvolvimento de taquicardia nos quadros de choque circulatório é inconstante. Potros hipovolêmicos que não apresentam elevação da frequência cardíaca frente ao estado de choque podem ter redução da liberação de $\mathrm{O}_{2}$ para os tecidos, resultando em dano tecidual. A ausência desta resposta fisiológica em alguns potros pode explicar, pelo menos em parte, a rápida deterioração clínica naqueles com choque circulatório. Infelizmente, outros sinais clínicos de choque circulatório observados nos equinos adultos não são consistentemente observados nos potros neonatos. Extremidades frias é outro mecanismo fisiológico de defesa, no qual a vasoconstrição nos membros e orelhas direciona o volume circulante restante para a circulação central e, desta forma, para os órgãos vitais. Esta resposta é inconstante nos potros e a presença de extremidades frias pode representar completa falha da circulação, sem perfusão adequada para qualquer órgão. Esta diferença é observada em potros hipotensos. A taquipnéia observada nos equinos adultos nos casos de choque representa uma resposta respiratória compensatória à acidose láctica resultante do metabolismo anaeróbico. No entanto, não é comumente observada nos potros (CORLEY; AXON, 2005).

O pulso arterial resulta da diferença entre a pressão diastólica e sistólica, sendo influenciado pelo tamanho do vaso, distância do coração e diferença entre a pressão sistólica e diastólica. Locais comumente utilizados para avaliação do pulso arterial são a artéria facial, facial transversa, carótida, safena, digital comum e coccígea. No equino, a frequência do pulso varia entre 28-40 pulsações por minuto. $\mathrm{O}$ aumento contínuo da frequência do pulso geralmente indica aumento da gravidade do choque, seja ele séptico ou hipovolêmico. A qualidade do pulso varia diretamente com a pressão do pulso e pressão sistólica. A identificação de um pulso fraco ou até mesmo a não identificação é indicativa de uma pressão sanguínea baixa e, consequentemente, prognóstico reservado à desfavorável. Na rotina clínica, a palpação digital do pulso pode fornecer uma avaliação relativa da pressão sistólica. A pressão sistólica arterial deve ser maior que $65 \mathrm{mmHg}$ e a pressão de pulso superior a $25 \mathrm{mmHg}$ para que o pulso possa ser identificado (SPEIRS, 1999).

A característica e coloração das mucosas, particularmente a escleral e a oral, são parâmetros importantes na avaliação do paciente em choque. A umidade da mucosa é um indicador confiável do grau de hidratação do equino. Mucosas ressecadas 
geralmente indicam algum grau de desidratação. Já a coloração da mucosa é variável indo desde rosa pálido ao vermelho forte e de pálida à cianótica. Nos estágios iniciais do choque, as mucosas apresentamse pálidas, e à medida que a hipoperfusão tecidual periférica se acentua as mucosas tornam-se cianóticas ou há formação de halo dentário cianótico (COLAHAN, 1985; MOORE, 1990).

O tempo de perfusão capilar (TPC) é outro parâmetro importante na avaliação do choque. Geralmente, o TPC é menor do que dois segundos nos equinos normais. TPC prolongado é geralmente indicativo de diminuição da perfusão capilar, resultante da hipovolemia. Com a hipovolemia, a frequência cardíaca aumenta na tentativa de melhorar a perfusão tecidual. Isto é muitas vezes acompanhado por diminuição na qualidade do pulso, palidez das mucosas e TPC prolongado (SPEIRS, 1999).

Confiar exclusivamente na avaliação da pressão sistólica é muito arriscado, pois mecanismos compensatórios a mantêm em níveis normais até uma perda de $30 \%$ da volemia. Atenção deve ser dirigida em relação às frequências cardíaca e respiratória, perfusão cutânea e pressão de pulso (diferença entre a pressão sistólica e diastólica). A diminuição do nível de consciência e da diurese são sinais precoces de choque (MARSON et al., 1998). Como a hipovolemia é um achado primário dos vários tipos de choque e o restabelecimento da pressão sanguínea um dos objetivos terapêuticos, a mensuração acurada e contínua de pressão sanguínea é essencial nos casos de choque (BEALE et al., 2004).

A pressão arterial sanguínea pode ser mensurada por dois métodos: direto e indireto. O monitoramento direto fornece avaliação contínua da pressão, todavia se constitui num método invasivo. As vantagens dessa técnica são a melhor acurácia, principalmente nos estados vasoconstritores. Desta forma, esse tipo de mensuração é ideal para pacientes em estado crítico, tais como aqueles em choque hipovolêmico. Os métodos indiretos incluem as mensurações manométricas e os métodos oscilométrico e Doppler. O valor no qual a leitura pode ser considerada hiper ou hipotensiva ainda não está bem estabelecido (CORLEY, 2002a; MAGDESIAN, 2004). A Tab. 2 demonstra os valores de referência para a pressão arterial na espécie equina.

Tabela 2. Valores de referência para a pressão sanguínea arterial equina.

\begin{tabular}{ccc}
\hline Pressão sanguínea & Potros neonatos & Equinos adultos \\
\hline Sistólica & $80-120 \mathrm{mmHg}$ & $111,8 \pm 13,3 \mathrm{mmHg}$ \\
Diastólica & $65-90 \mathrm{mmHg}$ & $67,7 \pm 13,8 \mathrm{mmHg}$ \\
\hline
\end{tabular}

Fonte: Adaptado de Johnson et al. (1976) e Vaala e House (2006).

A perfusão tecidual adequada geralmente é avaliada através da determinação dos índices funcionais de certos órgãos, embora nenhum desses índices isoladamente seja indicador confiável do restabelecimento da perfusão tecidual. Esses incluem anormalidades CID, função renal alterada (elevação dos níveis séricos de uréia e creatinina); função hepática alterada (elevação da concentração sérica das transaminases, desidrogenase láctica e bilirrubina), além de alteração da perfusão intestinal manifestada por íleo e má absorção. Outros marcadores da perfusão tecidual utilizados são o equilíbrio ácido-base, saturação venosa de $\mathrm{O}_{2}$ e concentração sérica de lactato (BEALE et al., 2004).

A saturação venosa central de oxigênio $\left(\mathrm{SvO}_{2}\right)$ retrata a medida do equilíbrio entre a oferta sistêmica e a demanda tecidual de oxigênio, tornando-se muito importante na avaliação e acompanhamento da resposta terapêutica. Os quadros hipodinâmicos 
aumentam o tempo de trânsito das hemácias na microcirculação, fazendo que a $\mathrm{SvO}_{2}$ torne-se baixa por aumento da extração de $\mathrm{O}_{2}$. Por outro lado, a $\mathrm{SvO}_{2}$ eleva-se em estados com captação tecidual deficiente de $\mathrm{O}_{2}$ ou por um quadro hiperdinâmico (SILVA et al., 2001; SIQUEIRA; SCHMIDT, 2003).

A $\mathrm{SvO}_{2}$ é dependente do débito cardíaco, consumo de $\mathrm{O}_{2}$, concentração de hemoglobina e saturação arterial de $\mathrm{O}_{2}$. $\mathrm{O}$ valor normal da $\mathrm{SvO}_{2}$ nos pacientes com choque circulatório varia em torno de $70 \%$, porém pode está elevado nos casos de choque séptico em decorrência da má distribuição do fluxo sanguíneo (SILVA et al., 2001). Outras variáveis que podem ser utilizadas como estimativa da oxigenação tecidual incluem a comparação da diferença de $\mathrm{O}_{2}$ arterio-venoso (A-V) (normal: $<50$ $\mathrm{mmHg}$ ), diferença da saturação de $\mathrm{O}_{2} \mathrm{~A}-\mathrm{V}$ (normal: $<30 \%$ ) ou comparação da diferença A-V de $\mathrm{CO}_{2}$ (normal: <-5) (DIVERS, 2003).

A hiperlactacemia é um achado comum nos quadros de choque circulatório nos seres humanos e animais domésticos, secundária ao metabolismo anaeróbico (SIQUEIRA; SCHMIDT, 2003; BEALE et al., 2004). Entretanto, alguns estudos têm sugerido que a elevação da concentração de lactato seja resultante da falha metabólica celular, em vez da hipoperfusão global. A diminuição do clearence hepático do lactato pode resultar em hiperlactacemia, e pacientes com choque circulatório podem apresentar injúria hepática mais grave do que os testes convencionais de função hepática demonstram (SILVA et al., 2001; DRIES, 2007). Outra causa de hiperlactacemia, não relacionada à hipóxia celular, é a inibição da oxidação do piruvato mediada pela endotoxina resultando em conversão aumentada de piruvato a lactato. $\mathrm{O}$ efeito da endotoxina na oxidação do piruvato não foi avaliado no equino, porém pode contribuir para o aumento da concentração de lactato nos quadros de choque séptico. Após a correção das causas da hipóxia celular, a concentração de lactato pode diminuir rapidamente, à medida que a produção diminui e o clearence aumenta, e retornar a valores normais (>2 mmol/L) em até duas horas (DIVERS, 2003; FRANKLIN; PELOSO, 2006).

O diagnóstico do tipo de choque circulatório pode ser baseado na determinação de variáveis hemodinâmicas através do monitoramento hemodinâmico conforme sumarizado na Tab. 3 .

\section{Tratamento}

A própria definição do choque circulatório, como uma redução crítica na perfusão tecidual por anormalidade do sistema circulatório,já se transforma em instrumento operacional para elaboração do seu tratamento, não existindo nenhum agente isolado capaz de revertê-lo (MARSON et al., 1998; DRIESSEN; BRAINARD, 2006). Dessa forma, o tratamento do choque circulatório é meramente de suporte. Os passos iniciais são a correção da causa inicial e auxílio aos mecanismos compensatórios naturais para manter o débito cardíaco, oxigenação tecidual e a perfusão periférica. Dependendo do tipo de choque, outras medidas terapêuticas poderão ser adotadas após a terapia inicial, a exemplo da antibioticoterapia.

Tabela 3. Variáveis hemodinâmicas e respiratórias nos diversos tipos de choque circulatório.

\begin{tabular}{lccccc}
\hline Tipo de choque & DC & RVP & PCP & PVC & SvO $_{2}$ \\
\hline Hipovolêmico & Baixo & Alta & Baixa & Baixa & Baixa \\
Cardiogênico & Baixo & Alta & Alta & Alta & Baixa \\
Obstrutivo & Baixo & Alta & Baixa & Alta & Baixa \\
Distributivo & Alto & Baixa & Variável & Variável & Alta \\
Séptico & Alto & Baixa & Variável & Variável & Alta \\
\hline
\end{tabular}

$\mathrm{DC}=$ débito cardíaco; $\mathrm{RVP}=$ resistência vascular periférica; $\mathrm{PCP}=$ pressão capilar pulmonar; $\mathrm{PVC}=$ pressão venosa central; $\mathrm{SvO}_{2}$ = saturação venosa central de oxigênio.

Fonte: Adaptado de Siqueira e Schmidt (2003). 


\section{Fluidoterapia}

Independente da etiologia do choque circulatório, a manutenção das pressões de enchimento ventricular em níveis adequados para produzir um débito cardíaco efetivo é o objetivo fundamental da reposição da volemia. A hipovolemia não é apenas uma das causas mais comuns de choque, como, também, pode existir em determinadas fases de todos os tipos de choque, incluindo o cardiogênico e o distributivo. Consequentemente, a reposição volêmica inicial faz-se necessária para expandir o volume intravascular visando corrigir a hipotensão, aumentar o fluxo sanguíneo renal e melhorar o nível de consciência (SIQUEIRA; SCHMIDT, 2003; DRIES, 2007).

O tipo de líquido utilizado na reposição dependerá da natureza da perda e da intensidade da mesma. A reposição volêmica pode ser realizada com cristalóide (ringer simples, ringer lactato, soro fisiológico) e/ou colóides (sangue e seus derivados, albumina, dextrans e aminas naturais e/ou sintéticas). Ambos os tipos de soluções possuem vantagens e desvantagens (Tab. 4) que devem ser consideradas no momento da escolha de qual tipo de fluido irá ser utilizado para o restabelecimento da normovolemia (HJELMQVIST, 2000).

Os cristalóides são soluções eletrolíticas que podem ou não conter açúcares de baixo peso molecular. São facilmente acessíveis e de baixo custo, estando disponíveis nas formas hipotônica, isotônica e hipertônica. As mais utilizadas são o ringer lactato e o soro fisiológico a 0,9\%. Estas soluções se equilibram livremente entre o espaço intravascular e intersticial, sendo eficazes em expandir ambos os compartimentos. Seu efeito hemodinâmico é máximo ao final da infusão, mas de curta duração (MAGDESIAN; MADIGAN, 2003).

Os cristalóides apresentam capacidade de expansão volêmica menor que os colóides, já que apenas $25 \%$ do volume infundido permanece no compartimento intravascular (MARSON et al., 1998; COOK; BAIN, 2003) após 30 minutos da administração (HASKINS, 1992). Nos pacientes em choque circulatório, o volume retido pode ser menor que 10\% (McFARLANE, 2000). Diferentemente do adulto, o equino neonato retém somente cerca 6 a $7 \%$ do volume de cristalóide administrado (PALMER, 2004).

Tabela 4. Vantagens e desvantagens dos cristalóides e colóides na reposição da volemia.

\begin{tabular}{lcc}
\hline Características & Cristalóide & Colóide \\
\hline Persistência intravascular & Baixa & Moderada \\
Estabilização hemodinâmica & Transitória & Prolongada \\
Volume de infusão necessário & Grande & Pequeno \\
Pressão osmótica coloidal & Reduzida & Mantida \\
Risco de hiperhidratação/edema tecidual & Moderado & Baixo \\
Elevação da perfusão capilar & Baixa & Moderada \\
Custo & Barato & Caro \\
\hline
\end{tabular}

Fonte: Hjelmqvist, 2000.

Evidências atuais indicam que o restabelecimento da volemia com cristalóides está associada a reduções na pressão coloidosmótica e, em alguns casos, ao edema pulmonar, sistêmico e cerebral, interferindo com a oxigenação tecidual. As soluções cristalóides contêm um ânion tamponante, seja o acetato ou o lactato. Aparentemente, as soluções contendo acetato são mais adequadas para o restabelecimento da volemia nos estados de choque, pois a capacidade do organismo metabolizar lactato pode estar diminuída nos estados de choque, independente da causa (HJELMQVIST, 2000; DRIESSEN; BRAINARD, 2006). 
O volume de fluido a ser administrado é estimado com base no déficit para reposição, requerimentos de manutenção e perdas futuras antecipadas. A velocidade de administração do fluido de reposição é determinada pelo quadro clínico do paciente, volume necessário para restabelecer a volemia, estimativas das perdas contínuas e, em alguns casos, do tempo disponível. Como guia geral, a velocidade pode variar de 10 a $20 \mathrm{ml} / \mathrm{kg} / \mathrm{h}$. No entanto, nos estados de choque velocidades tão altas quanto 50 a 100 $\mathrm{ml} / \mathrm{kg} / \mathrm{h}$ podem ser necessárias (SOUTHWOOD, 2004). Deve-se estar atento ao fato que velocidades muito rápidas podem provocar diurese pela rápida expansão plasmática, sem, contudo, permitir a difusão do fluido para outros compartimentos com déficits de volume. No entanto, grandes quantidades de fluido devem ser administradas em um equino com choque circulatório para que essa diurese seja observada (CORLEY, 2006).

Para potros neonatos a administração de bolus de fluido de $20 \mathrm{ml} / \mathrm{kg}$ durante 10 a 20 minutos com reavaliação da perfusão a cada bolus é mais eficiente do que a administração contínua de fluido. No entanto, repetidos bolus podem ser necessários para reverter o choque circulatório. Se uma dose maior que 60 a $80 \mathrm{ml} / \mathrm{kg}$ é necessária, a terapia vasopressora/inotrópica deve ser instituída. Em alguns potros, o retorno da perfusão adequada pode necessitar de até $200 \mathrm{ml} / \mathrm{kg}$ durante as primeiras duas horas (MAGDESIAN; MADIGAN, 2003; PALMER, 2004). No período inicial da reposição da volemia é importante a utilização de um cateter e sistema de distribuição de fluidos de grande diâmetro a fim de proporcionar a velocidade de infusão necessária. Muitas vezes há necessidade de cateterização das duas veias jugulares (direita e esquerda) para que altas velocidades de infusão sejam adotadas, além da utilização de bombas de infusão. Recomenda-se a utilização de cateteres de calibre $10 \mathrm{G}$ (galje) ou $14 \mathrm{G}$. Cateteres $14 \mathrm{G}$ podem ser utilizados nos potros em desmame ou equinos miniaturas (CORLEY, 2006).

Após correção do choque, a velocidade de infusão pode ser reduzida para 2 a $4 \mathrm{ml} / \mathrm{kg} / \mathrm{h}$ (velocidade de manutenção). Após a fase de reposição volêmica, deve-se adotar os valores diários de manutenção para a continuação da fluidoterapia. O requerimento de manutenção para equinos adultos varia de 40 a $60 \mathrm{~mL} / \mathrm{kg} /$ dia e para potros é 70 a $100 \mathrm{~mL} / \mathrm{kg} / \mathrm{dia}$ (MAGDESIAN; MADIGAN, 2003; PALMER, 2004).

A salina hipertônica $(\mathrm{NaCl} 7 \%$ ou 7,5\%) é utilizada em equinos com choque circulatório na dose de 4-5 $\mathrm{ml} / \mathrm{kg}$ para expandir rapidamente o volume intravascular. Devido a sua alta tonicidade, a administração intravenosa resulta em rápida expansão do volume plasmático pela retirada de água primariamente do fluido intersticial, principalmente do fígado e músculo, sem que ocorra reposição volêmica efetiva. A expansão do volume plasmático é de aproximadamente três vezes o volume infundido. Em decorrência da desidratação celular e meia-vida curta, após a administração da salina hipertônica deve-se administrar 10 litros de solução cristalóide isotônica para cada litro de salina hipertônica administrada (FANTONI et al., 1997). Como a salina hipertônica é um potente expansor plasmático, ela deve ser administrada com cuidado. Rápidas velocidades de infusão podem causar hipertensão, bradicardia e potencialmente agravar o estado de choque circulatório (DRIESSEN; BRAINARD, 2006). Outras complicações relatadas na literatura incluem elevação da concentração sérica de $\mathrm{Na}^{+}, \mathrm{Cl}^{-}$e da osmolalidade, além de diminuição na concentração de $\mathrm{HCO}_{3}^{-}$e K ${ }^{+}$. Arritmias, hemólise e hemoglobinúria são também relatadas (HASKINS, 1992).

As soluções salinas hipertônicas têm sido indicadas na ressuscitação pré-hospitalar do choque hemorrágico devido a sua capacidade superior em expandir o volume sanguíneo, elevar a pressão arterial e o débito cardíaco com volumes pequenos, com efeito praticamente instantâneo e duração de até quatro horas. Entretanto, alguns estudos demonstraram piora dos parâmetros hemodinâmicos e maior mortalidade, quando este tipo de solução 
é utilizada em hemorragias sem controle do foco hemorrágico (MARSON et al., 1998).

Recentemente, tem-se discutido o uso de solução salina hipertônica associada ao dextran 70 . O restabelecimento da volemia utilizando salina hipertônica/dextran está associado com melhora dos parâmetros hemodinâmicos e rápida correção da pressão sanguínea. Além disso, essa associação aumenta o fluxo da microcirculação pela redução do edema endotelial que pode ocorrer como parte da síndrome da resposta inflamatória sistêmica, melhorando, dessa forma, a perfusão tecidual. A adição de dextran prolonga a duração da ação da salina hipertônica em aproximadamente 30-90 minutos, entretanto, pode provocar hemólise e hemoglobinúria (McFARLANE, 2000; CORLEY, 2006).

Se a concentração da proteína plasmática total estiver abaixo de $3,5 \mathrm{~g} / \mathrm{dl}$ ou se suspeita que a administração de cristalóides promova a diminuição da concentração da proteína total para valores inferiores ao citado, os colóides devem ser o fluido de escolha. Os colóides são expansores plasmáticos mais efetivos do que os cristalóides e devem ser considerados quando não há resposta adequada a administração de cristalóides. Embora sejam mais caros do que os cristalóides, os colóides promovem rápida melhora da perfusão tecidual e a infusão de pequenos volumes promove o mesmo efeito clínico que grandes volumes de cristalóide. Dependendo do colóide administrado, ocorre um aumento do volume plasmático de aproximadamente $50 \%$ do volume infundido (HASKINS, 1992). Existem muitas suspensões coloidais disponíveis, com variedade no tamanho das moléculas, meia-vida, pressão coloidosmótica, efeitos colaterais e custo. Os agentes coloidais mais comumente utilizados para reposição volêmica incluem o sangue, plasma, albumina, dextran, hidroxietilamido (HES) e o penta-amido (MARSON et al., 1998; MAGDESIAN, 2003).

O sangue total pode ser indicado como a solução colóide de escolha nos casos de choque hemorrágico.
Complicações associadas com a utilização do sangue como colóide incluem as reações de incompatibilidade, anticorpos plasmáticos, bem como aquelas associadas com a transferências de leucócitos. O sangue total não é considerado um colóide concentrado e, dessa forma, grandes quantidades precisam ser administradas para que se alcance o resultado esperado (MAGDESIAN, 2003).

O plasma, um colóide natural, pode ser administrado para aumentar a concentração da proteína total, fornecer proteínas ativas a exemplo das proteínas de fase aguda, fatores de coagulação e antitrombina III, além de fornecer anticorpos para combater endotoxinas. Dessa forma, o plasma tem muitas vantagens sobre os colóides sintéticos. Uma dose de 2-4 ml/kg é necessária para manter a proteína plasmática acima de $4 \mathrm{~g} / \mathrm{dl}$ nos equinos adultos. Doses maiores $(10-20 \mathrm{ml} / \mathrm{kg})$ podem ser necessárias, principalmente nos quadros de choque onde há graves alterações da permeabilidade capilar. Já nos potros neonatos, doses variando entre 30-40 $\mathrm{ml} / \mathrm{kg}$ são relatadas na literatura. A administração do plasma é menos eficaz em expandir o volume plasmático do que os outros colóides (BELLI et al., 2008), portanto não deve ser utilizado como a solução de escolha para o restabelecimento da volemia nos casos de choque circulatório (SOUTHWOOD, 2004).

A albumina é responsável por cerca de $80 \%$ da pressão oncótica coloidal plasmática, e seu efeito após infusão depende primariamente da quantidade fornecida e não da concentração final da solução. Apenas 50\% do volume de solução de albumina administrado permanece no espaço intravascular após 3-4 horas, com o restante sendo redistribuído para o compartimento extravascular. Recentemente, Belli et al. (2008) avaliaram o efeito da administração da albumina em equinos com desidratação induzida. A utilização de albumina como fluidoterapia de reposição mostrou-se segura e nenhum efeito colateral foi obsrvado. 
O hidroxietilamido (Hetastarch) tem sido bastante utilizado nos equinos. Ele é disponível como uma solução aquosa a $6 \%$ em solução salina ou solução eletrolítica associada com lactato. Doses recomendadas de hidroxietilamido para equinos adultos variam entre 8 a $10 \mathrm{ml} / \mathrm{kg}$. Esta dose pode ser administrada na forma de bolus em animais hipovolêmicos ou como infusão lenta em equinos hipo-oncóticos. Efeitos colaterais relacionadas a administração de hidroxietilamido são o desenvolvimento de coagulopatias relacionas à diminuição da concentração do fator VIII e do fator de Von Willebrand. Reações de hipersensibilidade são raramente relatadas (MCFARLANE, 2000; MAGDESIAN, 2003).

A meia-vida do hidroxietilamido no equino é de aproximadamente seis horas e foi demonstrado experimentalmente que a administração deste colóide em animais com injúria de reperfusão resultou em significativa redução dos efeitos deletérios da injúria de isquemia/reperfusão quando comparado aos cristalóides, dextran ou albumina (SCHUSSER et al., 2007).

O dextran é um agente coloidal, polidisperso, preparado a partir de polímeros de glicose. Comercialmente, existem dois produtos: o dextran 40 e o 70. O dextran 40 é preparado sob a forma de solução hiperoncótica a $10 \%$, com peso médio de suas moléculas de 40.000 dáltons, tendo meiavida curta, porque muitas de suas moléculas são pequenas. $\mathrm{O}$ efeito hiperoncótico produz uma expansão inicial do volume intravascular, que é maior que o volume administrado. O dextran 70 é um colóide polidisperso, com média ponderada de pesos moleculares de 70.000 dáltons. Tem um tempo de retenção vascular maior que o dextran 40 . Ambos os dextrans podem melhorar a circulação microvascular por diminuir a viscosidade sanguínea e minimizar a agregação de plaquetas e hemácias (MARSON et al., 1998).

O dextran-40 tem meia-vida de duas horas, enquanto a do dextran-70 é seis horas. No equino, esses colóides são administrados na dose de $4 \mathrm{ml} /$ $\mathrm{kg}$ durante 15 a 20 minutos. Além de ser efetivo em restaurar rapidamente a volemia, o dextran inibe a agregação plaquetária e aderência leucocitária, resultando em efeitos antitrombóticos. Estes efeitos podem ser importantes no choque circulatório (McFARLANE, 2000).

\section{Reposição eletrolítica}

A importância da homeostase eletrolítica não pode ser desprezada durante o tratamento do choque. Após a correção da hipotensão e restabelecimento da perfusão tecidual adequada, a reposição de eletrólitos deve ser considerada. O potássio deverá ser reposto quando sua concentração sérica estiver abaixo de $3 \mathrm{mEq} / \mathrm{dl}$. O potássio geralmente é adicionado, empiricamente, aos fluidos isotônicos, em quantidade de 20 a $40 \mathrm{mEq} / 1$ e administrado a uma velocidade máxima de $0,5 \mathrm{mEq} / \mathrm{kg} / \mathrm{h}$. Nos equinos hipocalêmicos refratários à administração de cloreto de potássio, o magnésio deverá ser suplementado (CORLEY; MARR, 2003).

$\mathrm{O}$ cálcio é adicionado à fluidoterapia de manutenção numa quantidade de 25 a $50 \mathrm{~mL}$ de gluconato de cálcio $23 \%$ /litro de solução cristalóide isotônica, totalizando no máximo 200 a $300 \mathrm{~mL}$. A administração de $\mathrm{Ca}^{+}$intravenoso pode exacerbar o quadro de choque séptico, devendo ser administrado somente quando a concentração de cálcio ionizado estiver abaixo de $0,9 \mathrm{mmol} / \mathrm{L}(3,6 \mathrm{mg} / \mathrm{dl})$ ou quando o equino estiver apresentando sinais clínicos atribuídos a hipocalcemia. A hipocalcemia pode ser sequela da hipomagnesemia e, portanto, o magnésio deverá ser suplementado nos equinos hipocalcêmicos refratários à administração de gluconato de cálcio. O magnésio é suplementado pela adição de $1 \mathrm{~g}$ de sulfato de magnésio/litro de solução isotônica. O magnésio é um importante co-fator em muitas funções biológicas, incluindo a produção e uso do trifosfato de adenosina (ATP), coenzima das bombas de sódio-potássio e cálcio ATPase e regulação do equilíbrio intracelular do potássio (CORLEY; MARR, 2003; MELO et al., 2007a). 


\section{Drogas inotrópicas e vasopressoras}

Quando a fluidoterapia falha em restaurar a pressão arterial e a perfusão tecidual, a terapia com agentes inotrópicos e/ou vasopressores deve ser instituída. Este recurso terapêutico pode ser necessário temporariamente para manter a perfusão tecidual frente a hipotensão grave (BEALE et al., 2004; DRIES, 2007). Drogas inotrópicas são drogas que aumentam o débito cardíaco, principalmente por aumentar o volume força incluindo drogas como dobutamina, dopamina e epinefrina. Já as drogas vasopressoras aumentam a pressão sanguínea parcial ou totalmente através de um efeito vasoconstritor arteriolar direto e incluem drogas como a norepinefrina, fenilefrina e vasopressina (CORLEY, 2004).

$\mathrm{O}$ efeito das diferentes drogas citadas depende da sua afinidade pelos receptores adrenérgicos e dopaminérgicos (Tab. 5). Os receptores $\beta_{1}$ adrenérgicos elevam o débito cardíaco através da elevação da contratilidade cardíaca (inotropia) e da frequência cardíaca (cronotropia). Os receptores $\beta_{2}$ adrenérgicos medeiam a vasodilatação sistêmica, enquanto os receptores $\alpha$-adrenérgicos medeiam vasoconstrição. A distribuição dos receptores $\alpha$ e $\beta_{2}$-adrenérgicos no leito vascular varia entre os diversos órgãos, explicando os efeitos indesejáveis observados emalguns órgãos, mesmo, após a melhora da perfusão global. Os receptores dopaminérgicos do tipo $1\left(\mathrm{D}_{1}\right)$ medeiam vasodilatação, particulamente no leito vascular coronariano, renal, cerebral e visceral, enquanto os receptores dopaminérgicos do tipo $2\left(\mathrm{D}_{2}\right)$ medeiam vasodilatação através da inibição pré-sináptica da liberação de norepinefrina (CORLEY, 2004).

Tabela 5. Afinidade a receptores adrenérgicos e dopaminérgicos das diferentes drogas vasopressoras e inotrópicas utilizadas no equino.

\begin{tabular}{lcccccc}
\hline \multirow{2}{*}{ Droga } & \multicolumn{3}{c}{ Adrenérgico } & \multicolumn{2}{c}{ Dopaminérgico } \\
\cline { 2 - 6 } & $\beta_{1}$ & $\beta_{2}$ & $\alpha_{1}$ & $\alpha_{2}$ & $\mathrm{D}_{1}$ & $\mathrm{D}_{2}$ \\
\hline Dobutamina & +++ & ++ & + & + & 0 & 0 \\
Dopamina & ++ & + & ++ & $(+)$ & +++ & ++ \\
Epinefrina & +++ & +++ & +++ & +++ & 0 & 0 \\
Norepinefrina & +++ & 0 & +++ & +++ & 0 & 0 \\
Fenilefrina & $(+)$ & 0 & +++ & + & 0 & 0 \\
\hline
\end{tabular}

Fonte: Corley (2004). [+++: forte afinidade; ++ : moderada afinidade; + : afinidade fraca; $(+)$ : possível fraca afinidade; 0: nenhuma afinidade].

Caso não seja possível realizar a mensuração do débito cardíaco, a dobutamina deve ser o primeiro fármaco a ser administrado em equinos hipotensos (pressão arterial média inferior a 60 $\mathrm{mmHg}$ ) que não manifestaram resposta adequada à fluidoterapia. A dobutamina apresenta efeito predominante $\beta$-adrenérgico, responsável por sua ação inotrópica positiva e vasodilatadora periférica discreta, aumentando o débito cardíaco e diminuindo a resistência vascular periférica. Não libera norepinefrina endógena, induzindo menos taquicardia, arritmias e isquemia miocárdica do que a dopamina e noradrenalina. Não tem efeito vasodilatador renal, mas o volume urinário e o fluxo renal parecem aumentar igualmente em comparação com a dopamina, sugerindo que o aumento da perfusão renal, secundária ao aumento do débito cardíaco, é o mais importante determinante da manutenção da função renal (CORLEY, 2006; LONG; KIRBY, 2008).

A principal utilização clínica da dobutamina é como um inotrópico para aumentar a liberação de $\mathrm{O}_{2}$ para os tecidos. Por esta razão, indicadores 
específicos para a utilização da dobutamina são débito cardíaco baixo ou tensão de oxigênio venoso central diminuída, independente da fluidoterapia adequada (LONG; KIRBY, 2008). A dobutamina pode ter importante papel em melhorar a perfusão visceral quando vasopressores como a norepinefrina ou epinefrina são utilizadas, possivelmente pela sua ação nos receptores $\beta_{2}$-adrenérgicos. Portanto, baixas doses de dobutamina podem ser indicadas durante a terapia vasopressora. Nos estados hiperdinâmicos do choque, a dobutamina pode não ter efeito clínico sem que esteja associada a uma droga vasopressora (CORLEY, 2004). A dobutamina deve ser diluída em solução salina isotônica, glicose $5 \%$ ou ringer com lactato. A dose deve ser titulada cuidadosamente a partir de uma dose inicial de $1-3 \mu \mathrm{g} / \mathrm{kg} / \mathrm{min}$. O equino deve ser avaliado quanto à manifestação de taquicardia, o que em alguns casos pode indicar reposição volêmica inadequada e a existência de disritmias. Nos equinos com choque séptico e aumento do débito cardíaco, é pouco provável que a dobutamina melhore a perfusão e oxigenação tecidual (CORLEY, 2006).

Deve-se considerar a administração de noradrenalina em equinos hipotensos irresponsivos à administração de dobutamina ou que apresentam débito cardíaco elevado. A noradrenalina é um mediador adrenérgico natural, com potente efeito constritor venoso e arterial (alfa dependente) e modesto efeito inotrópico positivo (beta 1 dependente). A noradrenalina aumenta, predominantemente, a pressão arterial pela elevação da resistência vascular sistêmica e pode não melhorar, ou até diminuir o débito cardíaco. É utilizada, principalmente, no choque séptico e em condições de choque refratário. A noradrenalina deve ser diluída em solução de glicose a 5\%. A dose inicial é $0,1 \mu \mathrm{g} / \mathrm{kg} / \mathrm{min}$, no entanto, os efeitos de sua administração podem ser observados, em alguns equinos, com doses tão baixas quanto 0,01 $\mu \mathrm{g} / \mathrm{kg} / \mathrm{min}$. A infusão de noradrenalina associada à dobutamina $(5 \mu \mathrm{g} / \mathrm{kg} / \mathrm{min})$ em humanos resultou na melhora da perfusão tecidual e é recomendada principalmente quando o débito cardíaco não está sendo monitorado diretamente. É importante a monitoração cuidadosa do débito urinário quando se administra noradrenalina, pois, o uso de doses inadequadas pode reduzir o fluxo sanguíneo renal (WOHL; CLARK, 2000).

A dopamina é um precursor imediato da noradrenalina na via biossintética das catecolaminas. Estimula diretamente receptores alfa e beta adrenérgicos, ao mesmo tempo em que promove liberação de norepinefrina endógena. Doses baixas têm efeito basicamente dopaminérgico (aumento do fluxo renal). Doses intermediárias têm efeito, principalmente, beta-estimulante (inotrópico positivo) e doses altas possuem efeito alfa-estimulante (aumento da resistência vascular periférica) (WOHL; CLARK, 2000).

Alguns clínicos recomendam dopamina como vasopressor de primeira linha. A argumentação para tal recomendação é que a ação da dopamina nos receptores $\beta_{2}$-adrenérgicos e dopaminérgicos possa impedir a excessiva vasoconstrição em leitos vasculares vulneráveis, a exemplo da circulação visceral. Quando utilizada, a dopamina deve ser diluída em salina isotônica, glicose $5 \%$ ou solução de ringer com lactato. Se utilizada como inotrópica, a dose inicial deve ser de $2-5 \mu \mathrm{g} / \mathrm{kg} / \mathrm{min}$, mas se o objetivo for utilizá-la como vasopressora, a dose inicial deverá ser $5-10 \mu \mathrm{g} / \mathrm{kg} / \mathrm{min}$ (CORLEY, 2004).

A epinefrina é um forte agonista adrenérgico, sem atividade dopaminérgica. Embora a epinefrina seja um efetivo vasopressor, seus efeitos negativos sobre a circulação visceral pode limitar sua utilidade clínica. Diferentemente da norepinefrina, a epinefrina diminui o fluxo sanguíneo mesentérico. $\mathrm{O}$ principal uso clínico da epinefrina é como um agente vasopressor secundário, sendo utilizado quando a administração de dopamina ou norepinefrina falha em restaurar a pressão de perfusão orgânica adequada. No entanto, o prognóstico é desfavorável quando a epinefrina é utilizada com esses propósitos. 
Para sua administração, a epinefrina deve ser diluída em solução salina isotônica, glicose a $5 \%$ ou ringer com lactato. A dose deve ser cuidadosamente titulada para uma dose inicial de $0,1 \mu \mathrm{g} / \mathrm{kg} / \mathrm{min}$ (CORLEY, 2004).

\section{Fenilefrina}

A fenilefrina é um $\alpha$-agonista com pouco ou nenhum agonismo nos receptores $\beta$-adrenérgicos e dopaminérgicos. A curta meia-vida da fenilefrina implica que, como as outras catecolaminas, ela necessidade de administração a uma velocidade de infusão constante (WOHL; CLARK, 2000). A meia-vida da fenilefrina no equino não é mais longa do que a da norepinefrina, e os efeitos efeitos duram por até trinta horas após a interrupção da sua infusão. Se o clínico optar por utilizar a fenilefrina como droga vasopressora, ele deverá utilizá-la em conjunto com um $\beta$-agonista, a exemplo da dobutamina (CORLEY, 2004).

\section{Corticosteróides}

A eficácia terapêutica dos corticosteróides no tratamento do choque circulatório tem sido demonstrada em várias espécies. Entre os efeitos benéficos cita-se a estabilização de organelas e membranas celulares, manutenção do metabolismo celular e gliconeogênese, diminuição da produção endógena de mediadores inflamatórios, melhoria da microcirculação, diminuição de disfunção endotelial e da ativação e degranulação de leucócitos. Outros efeitos benéficos são a promoção de vasodilatação e aumento do DC (HASKINS, 1992; WADDEL et al., 1998). Independente dos efeitos benéficos, o uso dos corticosteróides no choque circulatório, especialmente no choque séptico, permanece controverso. As principais preocupações considerando a utilização de corticosteróides nos equinos são o risco de laminite e a potencial elevação da susceptibilidade à infecções em decorrência da inibição da migração de leucócitos e da atividade bactericida. Em virtude da possível interferência com a resposta do hospedeiro à infecção, uma única dose elevada é indicada nos casos de choque circulatório. Desta forma, metilprednisolona (30 $\mathrm{mg} / \mathrm{kg}$ ), dexametazona (6 $\mathrm{mg} / \mathrm{kg}$, podendo ser repetida após quatro horas se o choque persistir) ou hidrocortisona $(50-150 \mathrm{mg} / \mathrm{kg})$ podem ser administradas por via intravenosa (SOUTHWOOD, 2004).

\section{Oxigenação}

A administração de $\mathrm{O}_{2}$ é indicada nos pacientes hipoxêmicos $\left(\mathrm{PaO}_{2} \leq 60 \mathrm{mmHg}\right)$. Embora a oxigenioterapia seja recomendada e utilizada em pacientes hipoxêmicos, não existe uma correlação linear entre hipoxemia e hipóxia tecidual. Equinos com hipovolemia e hipoxemia devem ser tratados com fluidoterapia intravenosa antes ou durante a administração de $\mathrm{O}_{2}$. A elevação da $\mathrm{PaO}_{2}$ aumenta o tônus vascular sistêmico (exceto na artéria pulmonar, onde o efeito é o inverso) e diminui o débito cardíaco, ambos exacerbando déficits do fluxo sanguíneo. Embora o paciente em choque séptico esteja geralmente hiperventilando, a diminuição da perfusão periférica e consequente liberação inadequada de $\mathrm{O}_{2}$ aos tecidos durante as várias formas de choque indicam a necessidade do fornecimento de $\mathrm{O}_{2}$. O objetivo da terapia é manter o máximo da saturação de oxigênio na molécula de hemoglobina que é facilmente obtido com uma tensão de oxigênio sanguíneo arterial de 100 (CHEVALIER; DIVERS, 2003).

Oxigênio humidificado pode ser administrado por meio de cateter transtraqueal ou intranasal, tubo endotraqueal ou por um tubo inserido através de traqueostomia. Nos casos de administração intranasal de oxigênio, o comprimento do cateter necessário para alcançar a nasofaringe pode ser estimado pela mensuração da distância entre as narinas e o canto medial do olho. Um fluxo inicial de 10-15 litros/minuto de $\mathrm{O}_{2}$ é recomendado. Dependendo da gravidade da hipoxemia, a administração de $\mathrm{O}_{2}$ 
pode ser realizada uni ou bilateralmente (DUNKEL, 2006).

\section{Considerações finais}

O choque circulatório é uma síndrome clínica comum em equinos com abdome agudo ou naqueles sépticos. O reconhecimento precoce do choque circulatório e a instituição de uma terapêutica adequada são essenciais para a sobrevida do equino. Naqueles casos onde a terapêutica é falha ou tardia, a síndrome da disfunção orgânica múltipla pode surgir. Nos equinos, em particular, a síndrome da disfunção orgânica múltipla é manifestada comumente como laminite ou íleo adinâmico. Mesmo após a reversão do quadro de choque, alguns animais podem manifestá-lo novamente, sendo isto comumente observado naqueles casos onde a causa primária ou contribuinte para o desenvolvimento do choque circulatório não foram adequadamente tratadas. Mais pesquisas são necessárias para o completo entendimento dos mecanismos fisiopatológicos operantes para o desenvolvimento do choque circulatório, principalmente na espécie equina.

\section{Referências}

BASTERRECHEA, M.J.; STEIN, F. The association of sepsis with multiple organ dysfunction syndrome. Seminars in Pediatric Infectious Diseases, Philadelphia, v.11, n.1, p.68-72, 2000.

BEALE, R.J.; HOLLENBERG, S.M.; VICENT, J.L. et al. Vasopressor and inotropic support in septic shock: an evidence-based review. Critical Care Medicine, New York, v.32, n.11, p.455-465, 2004.

BELLI, C.B.; MICHIMA, L.E.S.; LATORRE, S.M. et al. Solução concentrada de albumina equina na fluidoterapia em equinos com desidratação leve a moderada. Arquivo Brasileiro de Medicina Veterinária e Zootecnia, Belo Horizonte, v.60, n.1, p.30-35, 2008.

BOTTOMS, G.D.; ADAMS, H.R. Involvement of prostaglandins and leukotrienes in pathogenesis of endotoxemia and sepsis. Journal American Veterinary Medical Association, Schaumburg, v.200, n.12, p.18421848, 1992.
CAMPEBELL, R.C.; PEIRÓ, J.R.; ROSA, P.C.S. et al. Endotoxemia por lipopolissacarídeo de Escherichia coli, em equinos: efeitos antiinflamatórios nas concentrações sérica e peritoneal do fator de necrose tumoral alfa (TNF- $\alpha$ ). Arquivo Brasileiro de Medicina Veterinária e Zootecnia, Belo Horizonte, v.59, n.4, p.837-843, 2007.

CARDOSO, L.M.; COLOMBARI, D.S.A.; MENANI, J.V. Espécies reativas de oxigênio no controle neurovegetativo da pressão arterial. Medicina, São Paulo, v.39, n.1, p.77-88, 2006.

CHEVALIER, H.; DIVERS, T.J. Pulmonary dysfunction in adult horses in the intensive care unit. Clinical Techniques in Equine Practice, Philadelphia, v.2, n.2, p.165-177, 2003.

COLAHAN, P.T. Evaluation of horses with colic and the selection of surgical treatment. Compendium on Continuing Education for in Practicing Veterinary, Trenton, v.15, n.3, p.141-149, 1985.

COOK, V.L.; BAIN, F.T. Volume (Crystalloid) replacement in the ICU patient. Clinical Techniques in Equine Practice, Philadelphia, v.2, n.2, p.122-129, 2003.

CORLEY, K.T.T. Monitoring and treating haemodynamic disturbances in critically ill neonatal foals. Part 1: haemodynamic monitoring. Equine Veterinary Education, New Market, v.14, n.5, p.270-279, 2002a.

Monitoring and treating haemodynamic

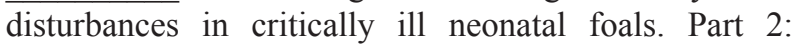
assessment and treatment. Equine Veterinary Education, New Market, v.14, n.6, p.328-336, 2002 b.

CORLEY, K.T.T.; MARR, C.M. Cardiac monitoring in the ICU patient. Clinical Techniques in Equine Practice, Philadelphia, v.2, n.2, p.145-155, 2003.

CORLEY, K.T.T. Inotropes and vasopressors in adults and foals. Veterinary Clinics of North America: Equine Practice, Philadelphia, v.20, n.1, p.77-106, 2004.

CORLEY, K.T.T.; AXON, J.E. Resuscitation and emergency management for neonatal foals. Veterinary Clinics of North America: Equine Practice, Philadelphia, v.21, n.2, p.431-455, 2005.

CORLEY, K.T.T. Fluidoterapia para equinos com enfermidades gastrintestinais. In: SMITH, B. P. (ed.). Medicina Interna de Grandes Animais. 3 ed. Barueri: Ed. Manole, 2006. p.682-694.

DALLAP, B.L. Coagulopathy in the equine critical care patient. Veterinary Clinics of North America: Equine Practice, Philadelphia, v.20, n.1, p.231-251, 2004. 
DEVEY, J.J.; CROWE JR., D.T. The physiologic response to trauma. Compendium on Continuing Education for in Practicing Veterinary, Trenton, v.19, n.8, p.962-973, 1997.

DIVERS, T.J. Monitoring tissue oxygenation in the ICU patient. Clinical Techniques in Equine Practice, Philadelphia, v.2, n.2, p.138-144, 2003.

DRIES, D. J. Cardiovascular support in septic shock. Air Medical Journal, Carlsbad, v.26, n.5, p.240-246, 2007.

DRIESSEN, B.; BRAINARD, B. Fluid therapy for the traumatized patient. Journal of Veterinary Emergency and Critical Care, San Antonio, v.16, n.4, p.276-299, 2006.

DUNKEL, B. Acute lung injury and acute respiratory distress syndrome in foals. Clinical Techniques in Equine Practice, Philadelphia, v.5, n.2, p.127-133, 2006.

FANTONI, D.T.; LIMA, F.A.; ALVARENGA, J. Uso da solução hipertônica de cloreto de sódio a 7,5\% no tratamento da hipotensão arterial decorrente da anestesia com halotano em equinos. Brazilian Journal Veterinary Research and Animal Science, São Paulo, v.34, n.6, p.327-331, 1997.

FERRARI, R. Importance of oxygen free radicals during ischemia and reperfusion in the experimental and clinical setting. American Journal Cardiology Pathology, Philadelphia, v.4, n.2, p.103-114, 1992.

FERREIRA, C.; PALHARES, M.S.; MELO, U.P. Peritonite em equinos: fisiopatologia, diagnóstico e tratamento. Revista CFMV, Brasília, n.42, p.48-60, 2007.

FERREIRA, C.; PALHARES, M.S.; MELO, U.P. et al. Cólicas por compactação em equinos: etiopatogenia, diagnóstico e tratamento. Acta Veterinaria Brasilica, Mossoró, v.3, n.3, p.117-126, 2009.

FRANKLIN, R.P.; PELOSO, J.G. Review of the clinical use of lactate. In: Annual Meeting of American Association Of Equine Practitioners, 52, 2006. Proceedings... AAEP, 2006. p.305-309.

FURR, M.O. Systemic inflammatory response syndrome, sepsis, and antimicrobial therapy. Clinical Techniques in Equine Practice, Philadelphia, v.2, n.1, p.3-8, 2003.

GREEN, E.L.; ADAMS, H.R. New perspective in circulatory shock: pathophysiologic mediators of the mammalian response to endotoxemia and sepsis. Journal American Veterinary Medical Association, Schaumburg, v.200, n.12, p.1834-1841, 1992.

HASKINS, S.C. Management of septic shock. Journal American Veterinary Medical Association, Schaumburg, v.200, n.12, p.1915-1924, 1992.
HJELMQVIST, H. Colloids versus crystalloids. Current Anesthesia and Critical Care, v.11, n.1, p.7-10, 2000.

HORMANSKI, C.E. Management of anaphylactic reactions. In: Annual Meeting of American Association of Equine Practitioners, 37, San Francisco, 1991. Proceedings... San Francisco: AAEP, 1991. p.61-70.

HOWE, L.M.; BOOTHE, H.W. Nitric oxide: a review for veterinary surgeons. Veterinary Surgery, Washington, v.30, n.1, p.40-47, 2001.

JOHNSON, J.H.; GARNER, H.E.; HUTCHESON, D.P. Ultrasonic measurement of arterial blood pressure in conditioned thoroughbreds. Equine Veterinary Journal, New Market, v.8, n.2, p.55-57, 1976.

KEEL, M.; TRENTZ, O. Pathophysiology of polytrauma. Injury, Bristol, v.36, n.6, p.691-709, 2005.

KUESIS, B.; SPIER, S.J. Endotoxemia. In: REED, S.M.; BAYLY, W.M. Medicina Interna Equina. Rio de Janeiro: Guanabara Koogan, 2000, p.550-561.

LONG, K.M.; KIRBY, R. An update on cardiovascular adrenergic receptor physiology and potential pharmacological applications in veterinary critical care. Journal of Veterinary Emergency and Critical Care, San Antonio, v.18, n.1, p.2-25, 2008.

MAGDESIAN, K.G. Colloid replacement in the ICU. Clinical Techniques in Equine Practice, Philadelphia, v.2, n.2, p.130-137, 2003.

MAGDESIAN, K.G.; MADIGAN, J.E. Volume replacement in the neonatal ICU: crystalloids and colloids. Clinical Techniques in Equine Practice, Philadelphia, v.2, n.1, p.20-30, 2003.

MAGDESIAN, K.G. Monitoring the critically ill equine patient. Veterinary Clinics of North America: Equine Practice, Philadelphia, v.20, n.1, p.11-39, 2004.

MARSON, F.; PEREIRA JUNIOR, G.A.; FILHO, A.P. A síndrome do choque circulatório. Medicina, São Paulo, v.31, n.3, p.369-379, 1998.

McFARLANE, D. Hetastarch: a synthetic colloid with potential in equine patients. Compendium on Continuing Education for in Practicing Veterinary, Trenton, v.21, n.9, p.867-884, 2000.

McMICHAEL, M.; MOORE, R.M. Ischemia-reperfusion injury pathophysiology, part I. Journal of Veterinary Emergency and Critical Care, San Antonio, v.14, n.2, p.231-241, 2004.

MELO, U.P.; PALHARES, M.S.; FERREIRA, C. Íleo adinâmico em equinos: fisiopatologia e tratamento. Arquivos de Ciências Veterinárias e Zoologia da UNIPAR, Umuarama, v.10, n.1, p.49-58, 2007a. 
MELO,U.P.;FERREIRA, C.; PALHARES, M.S. Doenças gastrintestinais em potros: etiologia e tratamento. Ciência Animal Brasileira, Goiânia, v.8, n.4, p.733-744, 2007 b.

MELO, U.P.; FERREIRA, C.; PALHARES, M.S. et al. Pericardite efusiva séptica em potro: relato de caso. In: Conferência Sul-americana de Medicina Veterinária, 8, Rio de Janeiro, 2008. 3p.

MOORE, J.N. Pathophysiology of circulatory shock. In: WHITE II, N. A. (ed.). The Equine Acute Abdome. Philadelphia: Lea \& Febiger, 1990. p.90-99.

MOORE, J.N.; MORRIS, D.M. Endotoxemia and septicemia in horse: experimental and clinical correlates. Journal American Veterinary Medical Association, Schaumburg, v.200, n.12, p.1903-1914, 1992.

MOORE, R.M.; MUIR, W.W.; GRANGER, D.N. Mechanisms of gastrointestinal ischemia-reperfusion injury and potential therapeutic interventions: a review and its implications in the horse. Journal of Veterinary Internal Medicine, Lakewood, v.9, n.2, p.115-132, 1995.

MOORE, J.N.; BARTON, M.H. An update on endotoxaemia. Part 1: mechanisms and pathways. Equine Veterinary Education, New Market, v.10, p.300-306, 1998.

MORRIS, D.D. Doenças do sistema hemolinfático. In: REED, S.M.; BAYLY, W.M. Medicina Interna Equina. Rio de Janeiro: Guanabara Koogan, 2000, p.481-518.

MUIR, W.W. Shock. Compendium on Continuing Education for in Practicing Veterinary, Trenton, v.20, p. 549-566, 1998.

OLSON, N.C.; HELlYER, P.W.; DODAM, J.R. Mediators and vascular effects in response to endotoxin. British Veterinary Journal, Oxford, v.151, n.5, p.489521, 1995.

PALMER, J.E. Fluid therapy in the neonate: not your mother's fluid space. Veterinary Clinics of North America: Equine Practice, Philadelphia, v.20, n.1, p.63-75, 2004.

PETERS, K.; UNGER, R.E.; BRUNNER, J. et al. Molecular basis of endothelial dysfunction in sepsis. Cardiovascular Research, London, v.60, n.1, p.49-57, 2003.

PINTÃO, M.C.T.; FRANCO, R.F. Coagulação intravascular disseminada. Medicina, São Paulo, v.34, n.2, p.282-291, 2001.
ROY, M.F. Sepsis in adults and foals. Veterinary Clinics of North America: Equine Practice, Philadelphia, v.20, n.1, p.41-61, 2004.

ROWE, E.L.; WHITE, N.A. Reperfusion injury in the equine intestine. Clinical Techniques in Equine Practice, Philadelphia, v.1, n.3, p.148-162, 2002.

SCHUSSER, G.F.; RIECKHOFF, K.; UNGEMACH, F.R. Effect of hydroxyethyl starch solution in normal horses and horses with colic or acute colitis. Journal Veterinary Medicine (Series A), Berlin, v.54, n.10, p.592-598, 2007.

SEAHORN, J.L.; SEAHORN, T.L. Fluid therapy in horses with gastrointestinal diseases. Veterinary Clinics of North America: Equine Practice, Philadelphia, v.19, n.3, p.665-680, 2003.

SILVA, E.; GARRIDO, A.G.; ASSUNÇÃO, M.S.C. Avaliação da perfusão tecidual no choque. Medicina, São Paulo, v.34, n.1, p.27-35, 2001.

SIQUEIRA, B.G.; SCHMIDT, A. Choque circulatório: definição, classificação, diagnóstico e tratamento. Medicina, São Paulo, v.36, n.2, p.145-150, 2003.

SPEIRS, V.C. Exame Clínico de Equinos. Porto Alegre: Editora Artes Médica Sul, 1999. 366p.

SOUTHWOOD, L.L. Postoperative management of the large colon volvulus patient. Veterinary Clinics of North America: Equine Practice, Philadelphia, v.20, n.1, p.167197, 2004.

SWIDERSKI, C.E. Overview of anaphylactic shock in horses. Compendium on Continuing Education for in Practicing Veterinary, Trenton, v.22, n.1, p.84-85;91-92, 2000.

VAALA, W.E.; HOUSE, J.K. Cuidados de suporte para o neonato anormal. In: SMITH, B. P. (ed.). Medicina Interna de Grandes Animais. 3 ed. Barueri: Ed. Manole, 2006. p.294-302.

WANG, P. Adrenomedullin and cardiovascular responses in sepsis. Peptides, Baton Rouge, v.22, n.11, p.18351840, 2001.

WOHL, J.S.; CLARK, T.P. Pressor therapy in critically ill patients. Journal of Veterinary Emergency and Critical Care, San Antonio, v.10, n.1, p.19-33, 2000. 
